\title{
The Effects of Dementia Knowledge on Dementia Worry, Attitudes, Social Comfort, Empathic Concern, and Personal Distress
}

\author{
Alexandria Rose Ebert \\ are0018@mix.wvu.edu
}

Follow this and additional works at: https://researchrepository.wvu.edu/etd

Part of the Clinical Psychology Commons, Developmental Psychology Commons, and the Geropsychology Commons

\section{Recommended Citation \\ Ebert, Alexandria Rose, "The Effects of Dementia Knowledge on Dementia Worry, Attitudes, Social Comfort, Empathic Concern, and Personal Distress" (2021). Graduate Theses, Dissertations, and Problem Reports. 8320. \\ https://researchrepository.wvu.edu/etd/8320}

This Thesis is protected by copyright and/or related rights. It has been brought to you by the The Research Repository @ WVU with permission from the rights-holder(s). You are free to use this Thesis in any way that is permitted by the copyright and related rights legislation that applies to your use. For other uses you must obtain permission from the rights-holder(s) directly, unless additional rights are indicated by a Creative Commons license in the record and/ or on the work itself. This Thesis has been accepted for inclusion in WVU Graduate Theses, Dissertations, and Problem Reports collection by an authorized administrator of The Research Repository @ WVU. For more information, please contact researchrepository@mail.wvu.edu. 
The Effects of Dementia Knowledge on Dementia Worry, Attitudes, Social Comfort, Empathic Concern, and Personal Distress

\author{
Alexandria R. Ebert, M.S. \\ Thesis submitted \\ to the Eberly College of Arts and Sciences \\ at West Virginia University \\ in partial fulfillment of the requirements for the \\ Master's of Science in \\ Psychology
}

Amy Fiske, Ph.D., Chair
Julie Hicks Patrick, Ph.D.
Barry Edelstein, Ph.D.
Natalie Shook, Ph.D.
Department of Psychology

Morgantown, West Virginia

2021

Keywords: Dementia, Empathic Concern, Personal Distress, Dementia Worry, Social Comfort, Personhood-based Knowledge, Biomedical Knowledge

Copyright 2021 Alexandria Ebert 


\begin{abstract}
The Effects of Dementia Knowledge on Dementia Worry, Attitudes, Social Comfort, Empathic
\end{abstract}

Concern, and Personal Distress

\begin{abstract}
Alexandria Ebert
The present study examined the effects of different types of dementia knowledge on attitudes and affective reactions towards persons with dementia. Work has demonstrated that individuals with higher levels of personhood-based knowledge have lower levels of personal dementia fear and higher levels of social comfort. However, to our knowledge, work has not examined dementia attitudes more broadly or differentiated causal relations among different forms of dementia knowledge and attitude outcomes. Participants $(\mathrm{N}=334)$ aged 19-78 $(M=44.53, S D=16.57)$ were randomized into one of five experimental conditions: (1) biomedical-knowledge (BK; read biological and medical facts about dementia), (2) personhood-based knowledge (PBK; read accounts of life experiences and capabilities written by persons living with dementia), (3) both BK and PBK, (4) control, and (5) active control. Participants then completed outcome measures. A significant effect of knowledge on personal distress and empathic concern $(p$ 's $<.01 .05$, respectively) emerged: groups did not significantly differ in attitudes, comfort, or dementia worry. Specifically, participants in the combined knowledge condition had higher levels of personal distress than those in the active control condition; they also had higher levels of personal distress than those in the baseline control condition. Those in the PBK condition had higher levels of empathic concern than those in the active control, and baseline control conditions. Overall, these results suggest that increasing personhood-based knowledge about dementia may be useful in fostering feelings of empathic concern, while a combination of both personhood-based knowledge and biomedical knowledge may be more likely to only induce personal distress.
\end{abstract}




\section{Table of Contents}

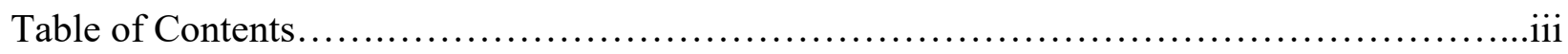

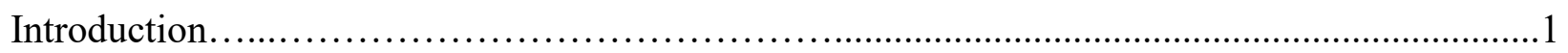

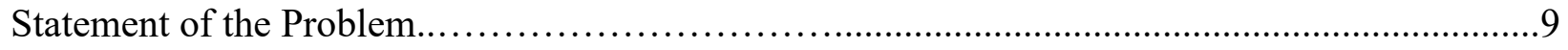

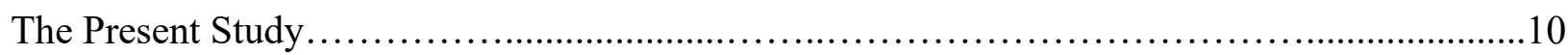

Research Questions and Hypotheses........................................................ 10

Methods........................................................................... 11

Participants.............................................................. 11

Procedures and Materials.................................................... 12

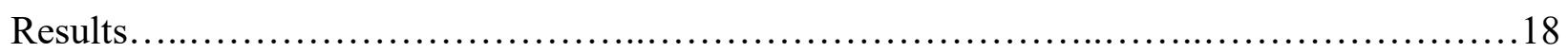

Age, Bot, Attention, and Manipulation Check..................................... 18

Missing Data Analyses.......................................................... 19

Checking for Assumptions/Outliers..........................................20

Manipulation Checks for Personhood-Based Knowledge and Biomedical Knowledge....21

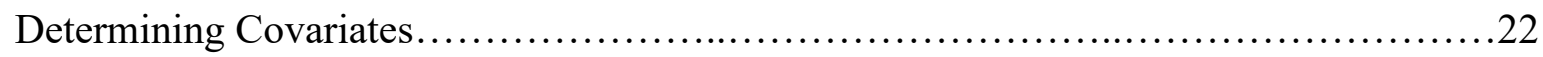

Primary Analyses...........................................................24

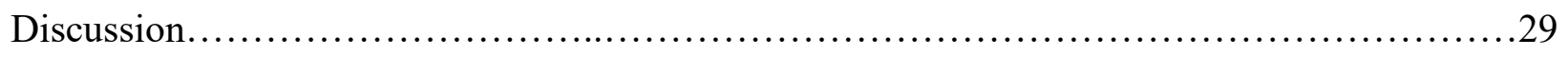

Limitations and Future Directions....................................................

Implications............................................................ 33

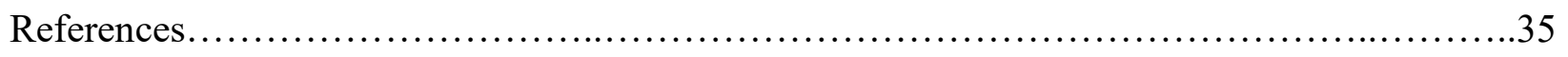

Tables and Figures................................................................

Table 1: Demographics by Condition........................................43

Table 2: Descriptives of Covariates and Outcome Variables.........................45 
Table 3: Bivariate Correlations Among Covariates and Outcome Variables................47

Table 4: Analysis of Covariance - Dementia Worry by Condition......................48

Table 5: Analysis of Covariance - Social Comfort by Condition.........................49

Table 6: Analysis of Covariance - Dementia Fear by Condition......................50

Table 7: Analysis of Covariance - Dementia Attitudes by Condition....................51

Table 8: Analysis of Covariance - Empathic Concern by Condition......................52

Table 9: Analysis of Covariance - Personal Distress by Condition.....................53

Table 10: Empathic Concern by Condition - Bonferroni Post-Hoc........................54

Table 11: Personal Distress by Condition - Bonferroni Post-Hoc......................55

Appendix A....................................................................... 56

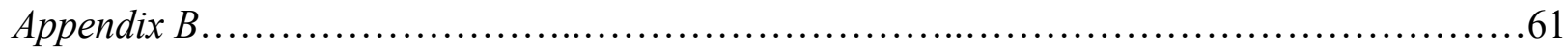

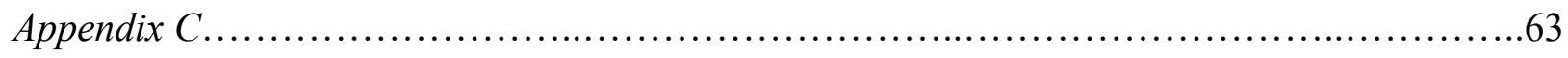

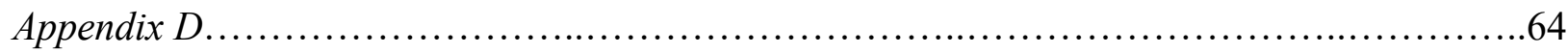

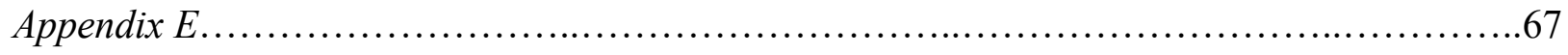

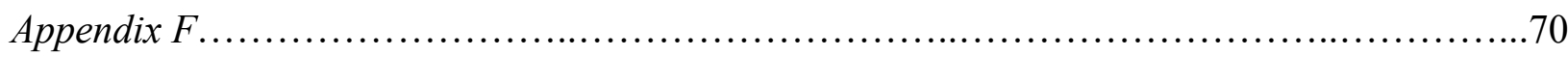

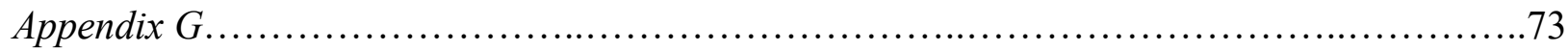

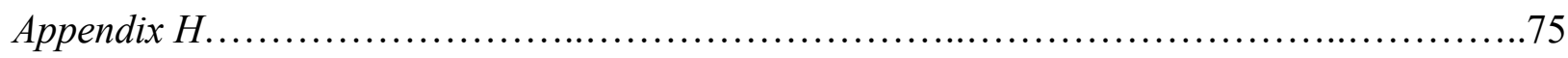

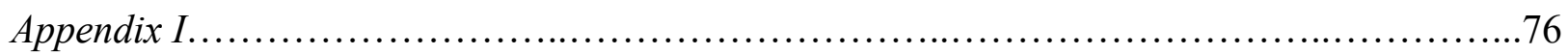

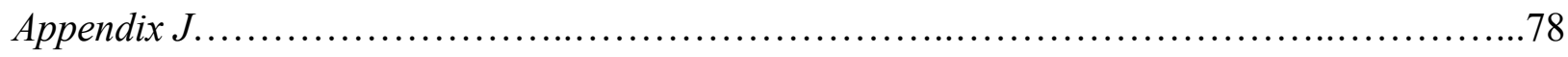

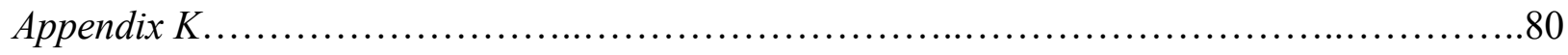

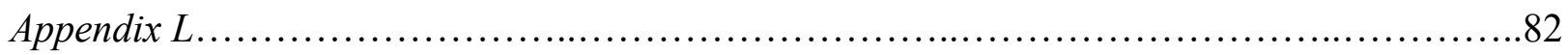

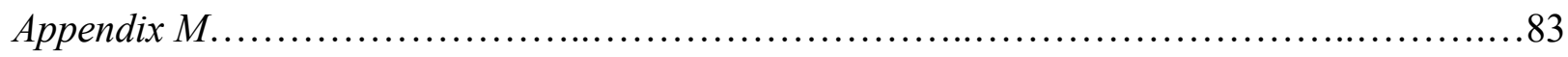

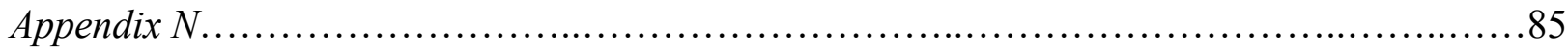


The Effects of Dementia Knowledge on Dementia Worry, Attitudes, Social Comfort, Empathic Concern, and Personal Distress

Dementia was deemed a public health priority by the World Health Organization in 2012. This neurocognitive disorder that affects 5.3 million Americans and 40 million individuals worldwide is expected to triple by 2050 (Alzheimer's Disease International, 2016; Prince et al., 2015). Dementia is not only terminal and degenerative, but also feared and stigmatized more in comparison to other terminal illnesses (Alzheimer's Society, 2007). The general narrative surrounding an older adult who has received a dementia diagnosis has been referred to as a "tragedy discourse" (e.g., overestimation of negative versus positive experiences and qualities of persons with dementia; Dupuis, Kontos, Mitchell, Jonas-Simpson, \& Gray, 2016; Mitchell, Dupuis, \& Kontos, 2017; Reed, Carson, \& Gibb, 2017). This narrative is in conflict with some research demonstrating that people with dementia and their family care-partners can still enjoy everyday aspects of their life and participate in meaningful forms of engagement (Fritsch et al., 2009; Kulibert, Ebert, Preman, \& McFadden, 2018; Swinnen \& de Medeiros, 2017). It is important to identify ways in which attitudes towards persons with dementia can be improved because negative attitudes and stigma towards persons with dementia affect both the person with the diagnosis (e.g., increased distress, self-stigma) and close-others (e.g., isolation; Milne, 2010). In order to understand how attitudes towards persons with dementia may be modified, the present study examined whether different descriptions of dementia lead to differences in attitudes and affective reactions people have towards persons with dementia.

First, models and theories explaining associations between stereotypes and affective or behavioral responses will be discussed. Stereotype Content Model, the Socio-Functional Approach to Prejudice, and the BIAS Map are models that may explain the relation between 
dementia stereotypes and the affective and behavioral responses they elicit. Next, Terror Management Theory, which explains associations between mortality salience and attitudes, affect, and behavior, will be discussed. Then, the cognitive and affective routes to attitude change will be discussed using the Tripartite Model of Attitudes. Finally, evidence for these routes of change that exist in the literature will be discussed.

Stereotype Content Model (SCM) has been used to explain universal principles of stereotypes and their impact on feelings and behaviors. SCM proposes that social perception occurs across two dimensions: (a) warmth (including traits such as trustworthy, friendly, sociable, and well-intentioned); and (b) competence (including traits such as being capable and skilled). These dimensions are thought to stem from the need to identify whether members of outgroups: (1) intend to enact harm/threaten access to resources; and (2) are capable of enacting harm and pose competitive threat to resources (Cuddy, Fiske, \& Glick, 2007; Fiske, Cuddy, Glick, \& Xu, 2002; Fiske, Xu, Cuddy, \& Glick, 1999; Fiske, et al., 2007). Typically, outgroups receive ambivalent evaluations, falling into either "kind but helpless" or "skillful but cunning" categories (e.g., high in warmth and low competence, or vice-versa; Cuddy et al., 2009, p. 3). Depending on the combination an individual or group falls into, they may instigate one of four emotions: (1) admiration, (2) contempt, (3) envy, or (4) pity (Fiske, Cuddy, \& Glick, 2002; Fiske et al., 2002). According to SCM (Fiske, 2015), older adults and individuals with disabilities are perceived as being high in warmth and low in competence and, therefore, instigate pity and sympathy from perceivers. Groups that instigate pity and/or sympathy typically are liked but disrespected (Glick \& Fiske, 2001a, 2001b; Jackman, 2001). Research has indicated that persons with dementia may also instigate ambivalent emotions of pity and sympathy. For example, when reading a vignette about a man with Alzheimer's disease, participants reported feelings of 
compassion and concern for the man, in addition to anxiety and aggression (Werner \& Davidson, 2004).

Furthering SCM, the BIAS Map (Cuddy, Fiske, \& Glick, 2007) predicts intergroup behaviors based on the dimensions of warmth and competence. These intergroup behaviors include active-passive concern (intensity) and harm-facilitation (valence). Active behaviors are defined as being “direct, explicit, overt, confrontational, intense, and high risk," whereas passive behaviors are "indirect, covert, less intense, and avoidant" (Cuddy, Fiske, \& Glick, 2007, p. 10). Discrimination can occur through either active or passive means (e.g., neglecting an outgroup member's welfare). The harm-facilitation component of intergroup behaviors can help predict prosocial/helping behavior versus antisocial/aggressive behavior (Batson, 1998; Geen, 1998). Active facilitation includes explicit intention to benefit a group, while active harm includes explicit intention to harm a group. Passive facilitation includes acceptance of an "obligatory association or convenient cooperation with a group," although contact with the group may not be desired (Cuddy, Fiske, \& Glick, 2007, p. 10). Passive harm includes demeaning or distancing from other groups "by diminishing their social worth through excluding, ignoring or neglecting" (Cuddy, Fiske, \& Glick, 2007, p. 10). Stemming from SCM, perceived warmth predicts valence of active behaviors, whereas perceived competence predicts valence of passive behaviors. Warmth may be given more weight in determining behavior in comparison to competence. As mentioned, older adults and persons with disabilities are typically perceived as being low in competence and high in warmth, which instigates pity. Pity is thought to instigate active facilitation and passive harm (e.g., neglect). Although this may lead to provisions of help to outgroup members, it may also lead to more social distancing and disrespect (e.g., patronizing speech, poor treatment; Weiner, 2005; Pasupathi \& Lockenhoff, 2002). 
Although most participants reading vignettes about persons with dementia typically do not register high levels of social distancing, participants with strong beliefs that they may develop dementia typically report higher levels of perceived threat and intentions to avoid persons with dementia (Werner, 2005). Given that stereotypes predict behavioral intentions of social distancing, it stands to reason that those with negative stereotypes regarding persons with dementia may avoid being around them. Work has demonstrated that family members and nursing home staff may experience discomfort while interacting with either their loved one or with other residents with dementia (Fritsch et al., 2009; Miron, Thompson, McFadden, \& Ebert, 2017), leading to potential avoidant behaviors. While empathic concern instigates helping behaviors (Batson, 2011) and may ensure that certain groups (particularly persons with dementia) are not dehumanized or perceived as less than (Halpern \& Weinstein, 2004), personal distress may instigate negative outcomes. For example, family members and professional caregivers frequently report feelings of stress, which may lead to a collapse in compassionate care, or burnout (McPherson, Hiskey, \& Alderson, 2016; Miron et al., 2017).

Cottrell and Neuberg's Socio-Functional Approach to Prejudice (2005) posits that individuals from different groups elicit different perceived threats to the social structures and processes of the in-group, in turn, provoking distinct emotions. Groups generally tend to have a norm of reciprocity. When others are perceived as unable or unwilling to reciprocate, they are perceived as a threat to the group's functioning. This model predicts that groups that are perceived to pose a threat of non-reciprocity evoke feelings of pity. Similarly, this model predicts that groups that increase perceived threat to physical safety instigate fear, which explains escape and avoidance behaviors. A person with dementia might increase the salience of this life-limiting condition, thus, increasing perceived threat to safety. Avoidance of persons with dementia may 
be explained by perceptions of threat of non-reciprocity in interactions with persons with dementia as well as perceptions of threat to safety, leading to feelings of pity and fear, respectively.

Finally, according to Terror Management Theory, an individual's behavior toward outgroup members changes after a death prime (Burke, Martens, \& Faucher, 2010; Greenberg, Pyszczynski, \& Solomon, 1986). Persons with dementia may serve as a death prime, instigating fear of mortality and of developing dementia, which may affect the ways in which individuals perceive and behave towards them (O'Connor \& McFadden, 2012). For example, people who have more concerns about developing dementia tend to feel more aggressive towards people with dementia and view them as dangerous (Werner \& Davidson, 2004; Werner, 2005). In other words, dementia worry may affect social behavior, leading people to "avoid reminders of dementia, including interacting with people living with dementia" (Kessler, Bowen, Baer, Froelich, \& Wahl, 2012, p. 281). These avoidance and fear-like associations are true not only of the general public, but also of family members of persons with dementia, who indicate an increased fear of interacting with their loved ones as their symptoms progress (Miron, McFadden, Nazario, \& Buelow, 2017). While other degenerative diseases primarily threaten an individual's physical abilities and independence, dementia poses unique threats to an individual's perceived personhood and humanity. Indeed, persons having dementia are sometimes referred to as the "living dead" (Behuniak, 2011, p. 70). Such may be why individuals experience high levels of dementia worry (also known as dementia-related anxiety, or persistent worries about developing dementia). It is important to identify ways in which dementia worry can be reduced because it has been associated with negative outcomes such as suicide ideation (Cui et al., 2019) and avoidance of persons with dementia (Kessler, Bowen, Baer, Forelich, \& Wahl, 2012). 
According to the Tripartite Model of Attitudes, there are several routes to attitude change: cognitive, affective, and behavioral (Kaiser \& Wilson, 2019; Rosenberg \& Hovland, 1960). Research supports the notion that thoughts mediate change in attitude (as summarized in Wood, 2000). Wood (2000) posited that there may be either a causal relation, whereby change in thoughts leads to change in attitudes, or mutual mediation of thoughts and attitudes, depending upon level of processing. Specifically, dual processing models of persuasion (e.g,, the Heuristic/Systematic Model of Chaiken et al., 1996, and the Elaboration Likelihood model of Petty \& Wegener,1998) explain that when individuals engage in effortful processing, information induces thoughts that influence attitudes. In contrast, in automatic (less effortful) processing, attitudes are based on easily available information, such as heuristic rules. In addition, Wood (2000) suggests that attitudes may influence thoughts (thoughts as after-the-fact justification for attitudes). Wood also noted that mood influences information processing and subsequent attitude change. Specifically, mood may impact attitude toward an attitude object (e.g., I feel sad, so I must dislike it), individuals may have a particular disposition for selective processing of information (e.g., happy people attend to information that is positive), or an attitude object may evoke particular affective responses that influence what information they attend to or recall (Wood, 2000). At least one study to date has examined the impact of modifying attitudes and responses towards persons with dementia through the cognitive and affective route (e.g., Kimzey, Smith, \& Alfred, 2016), however, we could not locate any studies beyond that. Work in other areas demonstrates that although changing affective responses towards groups may motivate attitude change, it may also lead to reactance, which may make attitude change less likely (e.g., Leventhal, 1970; Witte, 1992). 
Considering the theories described above, and the evidence that cognitions can change attitudes, enhancing knowledge about dementia among the general public may be an effective intervention to change attitudes toward persons with dementia as well as affective states. In line with the tragedy discourse surrounding dementia, much information and many medical depictions available may overestimate the negative experiences of persons with dementiaprompting primarily negative thoughts and feelings (e.g., perceiving persons with dementia as low in competence, instigation of pity), and, ultimately, behaviors (e.g., social distancing/rejection) towards these individuals. Incorporating both information about the biomedical aspects of dementia as well as the lived experiences of persons with dementia may combat the misinformation that surrounds dementia. Overall, in line with Cottrell's and Neuberg's (2005) Socio-Functional Approach to Prejudice and the BIAS Map (Cuddy, Fiske, \& Glick, 2007) this new profile of beliefs regarding persons with dementia may promote more positive affective reactions and attitudes towards persons with dementia.

The most common form of knowledge intervention tested in the dementia literature has been biomedical knowledge (biological and medical facts of dementia, often presented as true or false statements; Anderson, Day, Beard, Reed, \& Wu, 2009; Carpenter, Balsis, Otilingam, Hanson, \& Gatz, 2009; Connell, Roberts, \& McLaughlin, 2007; Connell, Roberts, McLaughlin, \& Akinleye, 2009; Werner, 2002). However, a new construct of knowledge developed by O'Connor and McFadden (2010), and referred to as "personhood-based knowledge," has been identified as another potential form of knowledge that could impact the way people think and feel about persons with dementia. Personhood-based knowledge reflects knowledge about the perspective and life experiences of people with dementia, likely being established from personal experiences with, and/or first-hand accounts of, people who have dementia (Ebert, Kulibert, \& 
McFadden, 2019). In line with SCM, exposure to accounts written by people with dementia that detail both strengths and capabilities, as well as weaknesses and deficits, may challenge the notion that they are incompetent and instigate lower levels of neglect and pity.

Two studies have examined the associations among personhood-based knowledge, social comfort (e.g., feelings of comfort interacting with persons having dementia), and dementia worry (Ebert, Kulibert, \& McFadden, 2019; Ebert, McFadden, \& Kulibert, 2019). Specifically, people with lower levels of dementia worry and people with higher levels of personhood-based knowledge about dementia had higher levels of social comfort towards persons with dementia (Ebert, Kulibert, \& McFadden, 2019). Further, people with higher levels of personhood-based knowledge about dementia had lower levels of dementia worry (Ebert, McFadden, \& Kulibert, 2019). However, it is not yet known if these are causal relations.

One study was identified in the literature that examined the effects of particular interventions in enhancing both personhood-based and biomedical knowledge. Specifically, Kimzey, Smith, and Alfred (2016) examined the effects of different educational experiences on biomedical knowledge about Alzheimer's Disease (AD) and the combined social comfort towards, and personhood-based knowledge about, persons with AD using O’Connor and McFadden's (2010) Dementia Attitudes Scale. Nursing students were randomized into either an online training module about AD, a one-day six hour clinical immersion experience with people with $\mathrm{AD}$ living in a memory care unit, or a non-dementia/non-aging related clinical rotation in community health. Students in the AD clinical immersion group showed a significant increase in AD knowledge from pre- to post-test and showed the most improvement in their combined personhood-based knowledge and social comfort scores over time. Nurses in the online training and control groups did not show any statistically significant changes in knowledge or social 
comfort.

\section{Statement of the Problem}

Preliminary work has demonstrated an association between personhood-based knowledge and both social comfort and personal dementia fear. Specifically, individuals with higher levels of personhood-based knowledge have lower levels of personal dementia fear and higher levels of social comfort (Ebert, Kulibert, \& McFadden, 2019). Additionally, Kimzey, Smith, and Alfred (2016) found that an increase in personhood-based knowledge about dementia led to an increase in social comfort towards persons with dementia. Given that stereotypes predict behavioral intentions of social distancing, the present study sought to examine behavioral intent through the same measure of social comfort towards persons with dementia. Further, prior work has not examined whether dementia knowledge leads to differences in dementia worry, which is a more well-documented and psychometrically tested construct than dementia fear. Thus, the present

study includes both variations of the construct: dementia fear and dementia worry. Additionally, most knowledge interventions have not been tested on community members - particularly brief knowledge interventions that differentially target personhood-based and biomedical based knowledge. Although gender differences have not been found in most work, these studies tend to have a limited number of male participants, perhaps posing a limitation to understanding differences in gender across these variables. Further, no studies were found that experimentally manipulated and tested the effects of both personhood-based and biomedical knowledge about dementia. Finally, the present study also measured attitudes and affective reactions (empathic concern and personal distress) to understand whether receiving different pieces of information about dementia may affect the extent to which persons with dementia evoke more/less prosocial emotions. 


\section{The Present Study}

The present study examined whether different forms of dementia-specific knowledge interventions led to different attitudes toward persons with dementia and different affective outcomes. Dementia attitudes were measured explicitly (via questionnaires). Participants were randomized into one of five conditions in which they received information about dementia: (1) biomedical-knowledge condition, (2) personhood-based knowledge condition, (3) both biomedical and personhood-based knowledge condition, and (4) a control condition, in which they did not receive any information about dementia, and (5) an active control condition, in which they read about visual impairment. Then, participants filled out questionnaires that examined differences in dementia worry, attitudes toward persons with dementia, including social comfort, as well as empathic concern and personal distress. Because the information manipulation included in this study is novel, the present study proposed the following research questions in addition to the two hypotheses:

Research Question 1: Based on tripartite theory and evidence of a cognitive route to behavior change (reviewed by Wood, 2000), the first aim of the study was to explore whether different dementia knowledge interventions would lead to differences in dementia worry and personal dementia fear. This is also based on the sociofunctional approach's prediction that threat leads to fear, thus, by altering level of threat by showing positive aspects of living with dementia, worry and fear should be lower.

Hypothesis 1: The personhood-based knowledge intervention will reduce personal dementia fear, in line with prior work demonstrating that personhood-based knowledge was a significant predictor of lower levels of fear of dementia (Ebert, McFadden, \& Kulibert, 2019). 
Research Question 2: Based on tripartite theory as well as evidence of a cognitive route to behavior change (reviewed by Wood, 2000), this second aim of the study was to explore whether different dementia knowledge interventions would lead to differences in social comfort towards persons with dementia. Further, based on the sociofunctional approach's prediction that threat leads to avoidance, if people are exposed to information about positive experiences of living with dementia, perceived threat may decrease and social comfort may be higher.

Hypothesis 2: The personhood-based knowledge intervention will increase social comfort towards persons with dementia, in line with prior work demonstrating that personhood-based knowledge was a significant predictor of social comfort towards persons with dementia (Ebert, Kulibert, \& McFadden, 2019).

Research Question 3: Based on the tripartite theory and evidence of the cognitive route to behavior change (reviewed by Wood, 2000), the third aim of the study was to explore whether different dementia knowledge interventions would lead to differences in explicit dementia attitudes.

Research Question 4: Based on the tripartite theory and evidence of the cognitive route to behavior change (reviewed by Wood, 2000), the fourth aim of the study was to explore whether different dementia knowledge interventions would lead to different levels of empathic concern and personal distress. This is also based on the SCM model, which predicts that groups seen as less incompetent are less likely to be pitied and neglected.

\section{Methods}

\section{Participants}

Participants (final $N=334$ after data cleaning; based on power analysis using G*Power in which effect size was small and power was .80 ) were recruited via TurkPrime. Specifically, the 
study was advertised on TurkPrime as the "Dementia Thoughts and Feelings Survey."

TurkPrime selection criteria included residing in the U.S. English speaking, and a 95\% approval rating on TurkPrime. Specific HITs were created to ensure adequate sampling across ages. HITs were created so that at least $23 \%$ of the sample was $65+, 20 \%$ was between $55-64,40 \%$ was 25 54. The mean age of participants was $44.53(S D=16.57$; range $=19-78)$, with a fairly equal distribution of gender (45.8\% male; $54.2 \%$ female), most identifying as Caucasian (75.1\%), and having a bachelor's level of education (40.7\%). Participants received $\$ 4$ for participating in the study. The study took participants approximately 40 minutes to complete. See Table 1 for overall participant demographics and breakdown of demographics by condition. This study was approved by the IRB.

\section{Procedure and Materials}

Procedure. First, participants read a cover letter in which they were told to click "yes" if they agreed to participate in the study (and were advanced to the next page of the study) or "no" if they did not agree to participate in the study (and were exited out of the study).

After consenting to participate, participants completed the pre-test measures of personhood-based and biomedical knowledge. Then, participants were randomized into one of five conditions: (1) biomedical-knowledge condition, (2) personhood-based knowledge condition, (3) combined (both biomedical and personhood-based knowledge) condition, (4) a baseline control condition, in which they did not receive any information about dementia, and (5) an active control condition, in which they read about vision impairment. Participants in conditions 1-3 or 5 received an information sheet about dementia or vision impairment and were then instructed to read the sheet before completing the questionnaires. Participants in condition 4 (baseline) were instructed immediately to complete the questionnaires. 
Following the information manipulation, participants completed a mood check questionnaire that measured affect, empathic concern, and personal distress. Then, participants completed a second set of counterbalanced questionnaires that contained measures for dementia attitudes (Kinney, Yamashita, \& Brown, 2017), worry or fear about developing dementia (Ebert, Kulibert, \& McFadden, 2019; Suhr \& Isgrigg, 2011), and social comfort towards persons with dementia (O'Connor \& McFadden, 2010). After completing the questionnaires, participants completed the post-test dementia knowledge questionnaires that assessed both biomedical (Ebert, Kulibert, \& McFadden, 2019) and personhood based knowledge (O’Connor \& McFadden, 2010) and answered questions that corresponded directly to the information sheet to ensure they were paying attention and retained the knowledge. After completing all study tasks, participants read a debriefing form and had to indicate that they read the form before proceeding to the end of the study in which they entered their unique MTurk worker ID and were given the study completion code to receive compensation.

Cover Letter. Participants were instructed to read the cover letter over and select "yes" if they willingly agreed to participate in the study or "no" if they did not willingly agree to participate in the study. If they selected yes, they were able to advance to the next page of the study. If they selected no, they were exited out of the study. See appendix A.

Information manipulation. Participants read 2-3 page information sheets about dementia (or vision impairment if in active control condition). The biomedical knowledge manipulation was created using peer reviewed journal articles and textbooks written about dementia. The primary focus was to provide information that is specifically covered in the biomedical knowledge scale. The personhood-based knowledge manipulation was created using several books written by, or on behalf of, persons with dementia. Snippets from these books were 
included to provide a depiction of the first-hand experiences and accounts of persons with dementia. The primary focus was to provide information that is specifically covered in the personhood-based knowledge scale. The combined knowledge manipulation required participants to read both the personhood-based and biomedical knowledge manipulations. The order in which participants read each of these was counterbalanced. The manipulations were first pre-tested with clinical psychology graduate students and undergraduate research assistants to determine if they provided correct information, were clear, and tapped into each of the items included on the personhood-based and biomedical knowledge measures. The manipulations were then sent to four dementia experts (Dr. Margaret Gatz, Dr. Brian Carpenter, Dr. Cameron Camp, and Dr. Benjamin Mast) who provided feedback on accuracy and completeness of information included in each. See appendices D, E, and F.

Mood check questionnaire. Participants completed a mood check questionnaire following the manipulation. On the first part of the questionnaire, participants completed the Positive and Negative Affect Schedule (PANAS-SF; Watson, Clark, \& Tellgan, 1988), in which they rated their emotions across a 5 -point Likert scale $(1=$ very slightly $/$ not at all $; 5=$ extremely $)$ to ensure they did not significantly differ across experimental conditions in levels of positive affect and negative affect. Positive affect was computed by averaging the 10 positively-valanced items and negative affect was computed by averaging the 10 negatively-valanced items. The psychometric properties of this scale have been evaluated (Watson, Clark, \& Tellegen, 1986). The PANAS has demonstrated acceptable internal consistency (Cronbach's coefficient alpha ranging from $.86-.90$ for positive affect and $.84-.87$ for negative affect). The correlation between the positive and negative affect scales is typically low (ranging from -.12 to -.23, demonstrating independence). The PANAS has also demonstrated acceptable test-retest reliability and 
generalizability to different samples (e.g., students vs. non-students). Further, the scale has construct validity and external validity. The PANAS had acceptable reliability for positive (alpha $=.88)$ and negative (alpha $=.92)$ affect. See appendix G.

Interest. One item assessing interest was included following the PANAS to ensure participants did not significantly differ across conditions in level of interest. See appendix G.

Empathic concern and personal distress. Eleven items were included at the end of the mood check questionnaire to measure empathic concern and personal distress. Empathic concern was measured using six items (compassionate, softhearted, warm, moved, tender, and sympathetic) averaged together and personal distress was measured using five items (distressed, alarmed, disturbed, upset, and uneasy) averaged together. These items were added to the PANAS and inclusion was based on previous research and the conceptualization of empathic concern and personal distress by Batson et al. (1987). Participants rated all items on a 5-point Likert-type scale $(1=$ very slightly/not at all; $5=$ extremely $)$. Empathic concern $(\alpha=.94)$ and personal distress $(\alpha=.91)$ each had acceptable reliability. See appendix G.

Social comfort. The comfort subscale of the Dementia Attitudes Scale (DAS; O'Connor \& McFadden, 2010) was used to measure social comfort towards persons with dementia. The Dementia Attitudes Scale was developed using structured interviews, exploratory factor analysis, convergent validity testing, and confirmatory factor analysis (O’Connor \& McFadden, 2010). The social comfort subscale includes 11 items rated on a 7-point Likert scale $(1=$ strongly disagree; 7 = strongly agree) and was used to assess how comfortable participants felt about people with dementia by having participants respond to statements such as, "I feel relaxed around people with dementia," and "I am afraid of people with dementia." Negatively worded items were reverse coded before computing the overall scale score by averaging the items. The 
psychometric properties of this scale have been evaluated (O'Connor \& McFadden, 2010) and demonstrate construct validity, convergent validity, and reliability. This subscale demonstrated acceptable internal consistency reliability $(\alpha=.90)$ in prior work (Ebert, Kulibert, \& McFadden, 2019) as well as in the current study ( $\alpha=87)$. See appendix H.

Worry or Fear About Developing Dementia. Two scales were used to measure worry or fear about developing dementia. First, the Dementia Worry Scale (Suhr \& Isgrigg, 2011) was used to measure dementia worry. This scale contains 12 items rated on a 5-point Likert scale $(1=$ not at all typical of me; $5=$ very typical of $m e$ ). The items are statements regarding personal worries/concerns regarding developing dementia. Overall score on this measure was calculated by averaging items together. This measure demonstrated acceptable internal consistency $(\alpha=.91)$ and test-retest reliability over an average of 3 weeks was $.89(p<.001)$ in prior work (Kinzer \& Suhr, 2016). In the present study, the measure had acceptable reliability (Cronbach's alpha $=$ .96). See appendix I.

Second, as described and developed by Ebert, Kulibert, and McFadden (2019), the Personal Dementia Fear measure includes 11 statements rated on a 5-point Likert scale $(1=$ never; $5=$ always) regarding the level of fear an individual has of developing dementia. These statements were drawn from the highest loading items in the "general fear" factor of the Fear of Alzheimer's Disease Scale (FADS; French, Floyd, Wilkons, \& Osato, 2012). Participants responded to statements such as "Even though my memory is good, I am still afraid of developing dementia," and "The more I learn about dementia, the more fearful I become of getting it." This measure was constructed for use in prior work, and demonstrated acceptable reliability ( $\alpha=.93$; Ebert, Kulibert, \& McFadden, 2019). This measure had acceptable reliability in the present study (Cronbach's alpha $=.95)$. See appendix J. 
Explicit dementia attitudes. The Allophilia scale (Kinney, Yamashita, \& Brown, 2016) was used to measure positive attitudes toward persons with dementia. This measure contains 16 statements that participants rate on a 6-point Likert scale $(1=$ strongly disagree; $6=$ strongly agree), with higher scores indicating more positive attitudes. Each subscale has demonstrated acceptable reliability ( $\alpha=.89-.90)$ Kinney, Yamashita, \& Brown, 2017) and construct validity. This measure had acceptable reliability in the present study (Cronbach's alpha $=95)$. See appendix K.

Manipulation check. Participants completed dementia knowledge questionnaires that assessed both biomedical (Ebert, Kulibert, \& McFadden, 2019) and personhood-based knowledge (O’Connor \& McFadden, 2010) at the beginning and end of the study (as pre-/postmeasures). They also answered open-ended questions regarding what they had just read in order to determine if they were paying attention and retained appropriate information. See appendices $\mathrm{B}$ and $\mathrm{C}$.

The personhood-based knowledge (knowledge about the perspective and life experiences of people with dementia, established from personal experiences with people who have dementia) measure is a subscale of the Dementia Attitudes Scale (O'Connor \& McFadden, 2010). Participants responded to 10 statements about people with dementia, such as, "Difficult behaviors may be a form of communication for people with dementia" by indicating the extent to which they agree/disagree with each statement using a 7-point Likert scale $(1=$ strongly disagree; $7=$ strongly agree) to assess levels of personhood-based knowledge. Scores on this scale were calculated by averaging items together. This scale demonstrated acceptable reliability pre- and post-manipulation (Cronbach's alpha $=.89$ and .91 , respectively). See appendix C. 
The biomedical knowledge measure was developed for use in prior work (Ebert, Kulibert, \& McFadden, 2019). As described in Ebert, Kulibert, and McFadden (2019), this measure includes 22 statements (either true or false) about people with dementia. Specifically, this measure includes 8 items developed by McParland, Devine, Innes and Gayle (2012) and 12 items from the Dementia Knowledge Assessment Tool Version Two (Toye, Lester, Popescu, McInerney, Andrews, \& Robinson, 2014). Examples from this scale include "Dementia is a disease of the brain," "Dementia is a mental illness," Dementia is a part of the normal process of aging," and "Dementia is another term for Alzheimer's." Responses to this scale include: yes, I believe this; no, I don't believe this; and, I'm unsure. Participants' responses were coded as either correct or incorrect for each item. Scale scores were created by adding up the number of correct responses. See appendix B.

Demographics. Participants completed a brief demographics questionnaire after completing all other study forms. See appendix M.

Debriefing. Participants were presented with a debriefing form at the end of the study that they were instructed to read through and were provided with contact information of the PI (Dr. Amy Fiske) in case they had any additional questions/concerns about the study. Participants were provided with more information about the study and were given the option to receive the knowledge intervention sheets for each of the dementia conditions. See appendix N.

\section{Results}

\section{Age, Bot, Attention, and Manipulation Checks}

First, responses to questions included throughout the study were examined to determine whether participants were truthful about their age, potential bots on MTurk (vs. human participants), were paying attention to the questions being asked, and understood the information 
they read in the experimental conditions. Participants provided both the year they were born at the beginning of the study and their age in years at the end of the study. If there was a discrepancy between estimated age based on birth-year and age reported, participants were eliminated $(n=21)$. Bot-detection questions included "what color is a yellow bird" (correct answer = yellow) and "where is the White House" (correct answers = D.C., Washington, D.C.). If participants failed these checks, they were eliminated $(n=28)$. Attention checks included a Likert scale item that requested participants respond with a "5," as well as an open ended question that asked participants what the questions they answered were about (correct answers included dementia, emotions, color of bird, where the white house is). Participants who did not answer correctly were eliminated $(n=13)$. Finally, the manipulation check included an open ended question asking participants about what they had just read (correct answers dependent on condition they were randomized into). Participants who did not answer correctly were eliminated $(n=16)$. Overall, the total number of participants eliminated who failed any one of these checks was $71(17.61 \%$ of the data). It should be noted that some participants failed multiple checks (thus accounting for elimination of 71 vs. 78 participants).

\section{Missing Data Analyses}

After the aforementioned checks occurred, participants to be included in analyses and variables were screened to determine percentage of missing data. There were not any participants who were missing data. Thus, there was no need to assess for patterns of missingness or to utilize mean imputation for missing data. Of note, within the Qualtrics surveys, participants were prompted with a notification indicating that they had missed filling in particular items that gave them the option to fill in the missing items then proceed, or proceed while leaving this blank. 
This, as well as eliminating participants who failed the bot, attention, and manipulation checks, may have contributed to participants to be used in analyses not missing any data.

\section{Checking for Assumptions/Outliers}

First, outliers were assessed for each variable. Participants with z-scores of +/- 3.29

(Field, 2013) were considered for omission from analyses. For dementia worry, two participants had z-scores ranging from .04 to .31 above the cut-off; these participants' scores were Winsorized (e.g., assigned the next highest score that was not an outlier; 4.08; Field, 2013). For personal distress, one participant had a z-score 0.23 above the cut-off, this score was Winsorized (assigned a score of 3.20). For negative affect, four participants had z-scores ranging from .42 to 0.84 above the cut-off. Scores of these outliers were Winsorized (assigned a score of 3.80).

Along these same lines, the assumption of normality was examined by assessing each calculated scale score for skew and kurtosis (cutoff score =+/- 3.29; Field, 2013). Dementia worry, personal distress, and negative affect were positively skewed. Additionally, negative affect exhibited kurtosis. The square root transformation was first used to address skew and resulted in remaining skew for dementia worry (5.88), personal distress (6.06), negative affect (9.97). Kurtosis for negative affect (2.92) was no longer significant after the square root transformation. Next, the log transformation was applied and resulted in remaining skew for dementia worry (3.67) and personal distress (3.76), and negative affect (7.90). Finally, the inverse transformation was applied and corrected skew for dementia worry (.03) and personal distress (-.31). Skew remained but was improved for negative affect (-3.85). Both skew and kurtosis were eliminated for empathic concern (-2.19 kurtosis; $2.16 \mathrm{skew})$. Thus, analyses were conducted using the inverse transformation for dementia worry, personal distress, empathic concern, and negative affect. 
Second, the assumption of continuous variables was met because each of the outcome variables were continuous (interval variables). Third, the assumption of independence was met because the conditions were independent of one another (between-group independence) and the scores of participants in each condition did not influence one another as they completed the study independently from one another and were only exposed to one condition (within-group independence).

Homogeneity of variance was assessed using the Levene's statistic (cutoff of $p<.05$ to indicate violation). This assumption was violated for empathic concern. For empathic concern, the Welch's F Statistic was utilized to interpret results.

\section{Manipulation Checks for Personhood-Based Knowledge and Biomedical Knowledge}

Paired-samples t-tests were conducted to determine whether there was a significant change in level of personhood-based knowledge and biomedical knowledge from pre-test to post-test within conditions.

In the personhood-based knowledge condition, personhood-based knowledge was significantly higher in the post- $(M=5.95, S D=.91)$ than pre-test $(M=5.67, S D=.77), t(62)=$ 4.47, $p<.001$. In the combined knowledge condition, personhood-based knowledge was significantly higher in the post $(M=6.09, S D=.83)$ than pre-test $(M=5.80, S D=.80), t(70)=$ $5.26, p<.001$. In the biomedical condition $(t(63)=-1.16, p=.25)$, active control condition $(t(67)$ $=-.83, p=.407)$, and baseline control condition $(t(64)=-1.36, p=.178)$, personhood-based knowledge did not significantly differ pre/post.

In the biomedical knowledge condition, biomedical knowledge was significantly higher in the post $(M=15.97, S D=2.79)$ than pre-test $(M=13.12, S D=3.47), t(63)=-8.97, p<.001$. In the combined knowledge condition, biomedical knowledge was significantly higher in the 
post $(M=15.37, S D=3.54)$ than pre-test $(M=12.79, S D=3.52), t(70)=-8.42, p<.001$. In the personhood-based knowledge condition, biomedical knowledge was significantly higher in the post $(M=13.05, S D=3.36)$ than pre-test $(M=12.22, S D=3.36), t(61)=-2.39, p<.05$. In the active control condition and baseline control condition, biomedical knowledge did not significantly differ pre/post, $t(67)=.78, p=.43$, and $t(64)=.57, p=.56$, respectively.

One way analyses of variance (ANOVAs) revealed that pre-test personhood-based knowledge scores $\left(F(4,329)=.85, p=.495, \eta^{2}=.010\right)$, post-test personhood-based knowledge scores $\left(F(4,329)=.90, p=.464, \eta^{2}=.011\right)$, or pre-test biomedical knowledge scores, $(F(4,329)=$ $1.54, p=.191, \eta^{2}=.018$ ) did not differ by experimental condition. There was, however, a significant effect of experimental condition on post-test biomedical knowledge scores, $F(4,325)$ $=16.23, p<.001, \eta^{2}=.165$. Tukey's post-hoc tests revealed that participants in the biomedical knowledge condition had significantly higher biomedical knowledge post-test scores than those in the personhood, active control, and baseline control conditions. Participants in the combined knowledge condition had significantly higher biomedical knowledge post-test scores than those in the personhood-based knowledge condition, the active control condition, and the baseline condition.

\section{Determining Covariates}

A series of one-way analyses of variance (ANOVAs) were conducted to determine if conditions differed with respect to positive affect, negative affect, interest, boredom, and age. Dementia exposure, sex, and age were pre-determined to be utilized as a covariate in analyses.

Conditions did not significantly differ based on positive affect, $F(4,329)=.597, p=.665$, $\eta^{2}=.007$, or age, $F(4,329)=1.248, p=.290, \eta^{2}=.015$. 
Conditions did significantly differ based on negative affect, $F(4,329)=9.98, p<.001, \eta^{2}$ $=.108$. Because there were approximately equal sample sizes across groups and the assumption of homogeneity was not violated, Tukey Post Hoc tests were conducted to follow up the effect and examine group differences. The results from the post hoc test revealed that participants in the personhood-based knowledge condition $(M=1.74, S D=.77)$ had significantly higher levels of negative affect than participants in the active $(M=1.22, S D=.56)$ and baseline $(M=1.31, S D=$ $.51)$ control conditions $(p<.01)$. Participants in the biomedical knowledge condition $(M=1.58$, $S D=.63$ ) had significantly higher levels of negative affect than those in the active and baseline control conditions $(p<.01)$. Participants in the combined knowledge condition had significantly higher levels of negative affect $(M=1.60, S D=.62)$ than those in the active and baseline control conditions $(p<.01)$.

Conditions also significantly differed based on level of interest, $F(4,329)=2.886, p<$ $.05, \eta^{2}=.034$. The results from the post hoc test revealed that participants in the active control condition $(\mathrm{M}=3.62, \mathrm{SD}=1.08)$ had significantly lower levels of interest than those in the combined knowledge condition $(M=4.14, S D=.96 ; p<.05)$.

A chi-square test was conducted to determine if conditions differed with respect to gender and revealed that participants did not significantly differ based on gender, $X^{2}(4, N=334)$ $=5.47, p=.243$.

A chi-square test was conducted to determine if conditions differed with respect to dementia exposure and revealed that participants did not significantly differ based on dementia exposure, $X^{2}(4, N=334)=2.00, p=.736$. 
A chi-square test was conducted to determine if conditions differed with respect to education and revealed that participants did not significantly differ based on education, $X^{2}$ (4, $N$ $=334)=16.37, p=.693$.

A chi-square test was conducted to determine if conditions differed with respect to ethnicity and revealed that participants did not significantly differ based on ethnicity, $X^{2}$ (4, $N=$ $334)=24.27, p=.446$.

Both negative affect and interest were used as covariates in the analyses due to conditions varying at a statistically significant level on these two variables.

\section{Primary Analyses}

A series of ANCOVAs were conducted to examine the effect of experimental condition (personhood-based knowledge, biomedical knowledge, both forms of knowledge, baseline control, active control) on dementia worry, personal dementia fear, attitudes, social comfort, empathic concern, and personal distress. Exposure, interest, negative affect, age, and sex were controlled for in the ANCOVAs.

Hypothesis 1/Research Question 1: When including covariates in the model, there was not a significant effect of condition on personal dementia fear, $F(4,324)=.633, p=.639, \eta^{2}=$ .008 . Levene's test was not violated $(p=.315)$.

When conducting analyses without covariates, there was not a significant effect of condition on personal dementia fear, $\mathrm{F}(4,329)=.357, \mathrm{p}=.082, \eta^{2}=.021$. Levene's test was not violated $(\mathrm{p}=.088)$

When including covariates in the model (using transformed variables), there was not a significant effect of condition on dementia worry, $F(4,324)=.497, p=.738, \eta^{2}=.006$. Levene's test was not violated $(p=.555)$. 
When conducting analyses without covariates, there was not a significant effect of condition on dementia worry, $\mathrm{F}(4,329)=2.173, \mathrm{p}=.071, \eta^{2}=.022$. Levene's test was not violated $(\mathrm{p}=.630)$

In order to determine whether transformation of variables led to differences in effects, analyses were repeated with untransformed variables. When conducting analyses with covariates, there was not a significant effect of condition on dementia worry, $F(4,324)=2.234, p$ $=.065, \eta^{2}=.022$. Levene's test was not violated $(\mathrm{p}=.807)$.

When conducting analyses without covariates, there was not a significant effect of condition on dementia worry, $\mathrm{F}(4,329)=1.930, \mathrm{p}=.105, \eta^{2}=.019$. Levene's test was not violated $(\mathrm{p}=.137)$.

Hypothesis 2/Research Question 2: When including covariates in the model, there was not a significant effect of condition on social comfort, $F(4,324)=.367, p=.832, \eta^{2}=.005$. Levene's test was not violated $(p=.898)$.

When conducting analyses without covariates, there was not a significant effect of condition on social comfort, $\mathrm{F}(4,329)=.357, \mathrm{p}=.839, \eta^{2}=.004$. Levene's test was not violated $(\mathrm{p}=.857)$

Research Question 3: When including covariates in the model, there was not a significant effect of condition on explicit dementia attitudes, $\mathrm{F}(4,324)=.713, \mathrm{p}=.538$, partial eta squared $=.009$. Levene's test was not violated $(p=.995)$.

When conducting analyses without covariates, there was not a significant effect of condition on explicit dementia attitudes, $\mathrm{F}(4,322)=1.321, \mathrm{p}=.261, \eta^{2}=.013$. Levene's test was not violated $(\mathrm{p}=.291)$. 
Research Question 4: When including covariates in the model (using transformed variables), there was a significant effect of condition on empathic concern, Welch's $F(4,324)=$ $3.197, p<.05, \eta^{2}=.038$. Bonferroni Post-Hoc tests were conducted to follow up the effect and examine group differences. Participants in the personhood-based knowledge condition had significantly higher levels of empathic concern $(M=3.73 ; S D=.92)$ than those in the active $(M$ $=2.62 ; S D=1.19)$ and control $(M=2.85, S D=1.19)$ conditions $(p s<.01)$.

When conducting analyses without covariates, there was a significant effect of condition on empathic concern, $\mathrm{F}(4,329)=13.443, \mathrm{p}<.001, \eta^{2}=.120$. Levene's test was violated $(\mathrm{p}<$ .01). Because there were approximately equal sample sizes across groups, along with violation of normality, Bonferroni Post-Hoc tests were conducted to follow up the effect and examine group differences. Participants in the combined knowledge condition $(\mathrm{M}=1.86$; $\mathrm{SD}=.31)$ had significantly higher levels of empathic concern than those in the active control $(\mathrm{M}=1.61 ; \mathrm{SD}=$ $.36)$ and baseline control $(\mathrm{M}=1.66 ; \mathrm{SD}=.37)$ conditions $(\mathrm{ps}<.001)$. Participants in the personhood condition $(\mathrm{M}=1.92 ; \mathrm{SD}=.24)$ had significantly higher levels of empathic concern than those in the biomedical $(\mathrm{M}=1.74 ; \mathrm{SD}=.32)$, active control, and baseline control conditions $($ ps $<.01)$.

In order to determine whether transformation of variables led to differences in effects, analyses were repeated with untransformed variables. When conducting analyses with covariates, there was a significant effect of condition on empathic concern, $F(4,324)=5.849$, $\mathrm{p}<$ $.001, \eta^{2}=.057$. Levene's test was not violated $(\mathrm{p}=.484)$. Because there were approximately equal sample sizes across groups, Bonferroni Post-Hoc tests were conducted to follow up the effect and examine group differences. Participants in the combined knowledge condition $(\mathrm{M}=$ 3.58; $\mathrm{SD}=1.06$ ) had significantly higher levels of empathic concern than those in the active 
control $(M=2.72 ; S D=1.16)$, baseline control $(M=2.88 ; S D=1.15)$, and biomedical conditions $(\mathrm{M}=3.14 ; \mathrm{SD}=1.06)(\mathrm{ps}<.001)$. Participants in the personhood condition $(\mathrm{M}=$ 3.75; $\mathrm{SD}=.88$ ) had significantly higher levels of empathic concern than those in the biomedical, active control, and baseline control conditions ( $\mathrm{ps}<.01)$.

When conducting analyses without covariates, there was a significant effect of condition on empathic concern, $\mathrm{F}(4,329)=13.671, \mathrm{p}<.001, \eta^{2}=.122$. Levene's test was violated $(\mathrm{p}<$ .01). Because there were approximately equal sample sizes across groups, along with violation of normality, Bonferroni Post-Hoc tests were conducted to follow up the effect and examine group differences. Participants in the combined knowledge condition $(\mathrm{M}=3.58$; $\mathrm{SD}=1.06)$ had significantly higher levels of empathic concern than those in the active control $(\mathrm{M}=2.72 ; \mathrm{SD}=$ $1.16)$ and baseline control $(\mathrm{M}=2.88 ; \mathrm{SD}=1.16)$ conditions $(\mathrm{ps}<.001)$. Participants in the personhood condition $(\mathrm{M}=3.75 ; \mathrm{SD}=.88)$ had significantly higher levels of empathic concern than those in the biomedical $(\mathrm{M}=3.14 ; \mathrm{SD}=1.06)$, active control, and baseline control conditions $(\mathrm{ps}<.01)$.

When including covariates in the model (using transformed variables), there was a significant effect of condition on personal distress, $F(4,324)=5.036, p<.01, \eta^{2}=.059$. Because there were approximately equal sample sizes across groups and the assumption of homogeneity was not violated (Levene's $p=.733$ ), Bonferroni Post-Hoc tests were conducted to follow up the effect and examine group differences. Participants in the combined knowledge condition $(M=$ 2.05; $S D=.92$ ) had significantly higher levels of personal distress than those in the active control condition $(M=1.34, S D=.61, \mathrm{p}<.01)$ and baseline condition $(M=1.48, S D=.67, \mathrm{p}<.05$

When conducting analyses without covariates, there was a significant effect of condition on personal distress, $\mathrm{F}(4,329)=14.123, \mathrm{p}<.001, \eta^{2}=.125$. Levene's test was violated $(\mathrm{p}<.01)$. 
Because there were approximately equal sample sizes across groups, along with a violation of normality, Bonferroni Post-Hoc tests were conducted to follow up the effect and examine group differences. Participants in the combined knowledge condition $(\mathrm{M}=.57 ; \mathrm{SD}=.25)$ had significantly higher levels of personal distress than those in the active $(\mathrm{M}=.81 ; \mathrm{SD}=.25)$ and baseline $(\mathrm{M}=.76 ; \mathrm{SD}=.27)$ control conditions ( $\mathrm{ps}<.01)$. Participants in the personhood-based knowledge condition $(\mathrm{M}=.58 ; \mathrm{SD}=.26)$ had significantly higher levels of personal distress than those in the active and baseline control conditions (ps $<.01)$. Participants in the biomedical knowledge condition $(\mathrm{M}=.61 ; \mathrm{SD}=.28)$ had significantly higher levels of personal distress than those in the active and baseline control conditions (ps $<.05)$.

In order to determine whether transformation of variables led to differences in effects, analyses were repeated with untransformed variables. When conducting analyses with covariates, there was not a significant effect of condition on personal distress, $F(4,324)=1.426$, $\mathrm{p}=.225, \eta^{2}=.014$. Levene's test was violated $(\mathrm{p}<.01)$.

When conducting analyses without covariates, there was a significant effect of condition on personal distress, $\mathrm{F}(4,329)=10.352, \mathrm{p}<.001, \eta^{2}=.095$. Levene's test was violated $(\mathrm{p}<.01)$. Because there were approximately equal sample sizes across groups, along with violation of normality, Bonferroni Post-Hoc tests were conducted to follow up the effect and examine group differences. Participants in the combined knowledge condition $(\mathrm{M}=2.15 ; \mathrm{SD}=.97)$ had significantly higher levels of personal distress than those in the active $(\mathrm{M}=1.44 ; \mathrm{SD}=.70)$ and baseline $(\mathrm{M}=1.61 ; \mathrm{SD}=.92)$ control conditions ( $\mathrm{ps}<.01)$. Participants in the personhood-based knowledge condition $(\mathrm{M}=2.16 ; \mathrm{SD}=1.04)$ had significantly higher levels of personal distress than those in the active and baseline control conditions (ps $<.01)$. Participants in the biomedical 
knowledge condition $(\mathrm{M}=2.10 ; \mathrm{SD}=1.09)$ had significantly higher levels of personal distress than those in the active and baseline control conditions $(\mathrm{ps}<.05)$.

Overall, there were only minor differences found in post-hoc tests amongst analyses conducted with transformed versus untransformed variables. In other words, use of transformed variables did not produce major differences (e.g., changes in effects) in outcomes of analyses. Nonetheless, in order to maintain robustness of the study's findings, the analyses conducted that included transformed variables were used.

\section{Discussion}

Overall, experimental manipulation of dementia knowledge produced differences in levels of empathic concern and personal distress. Specifically, participants in the personhoodbased knowledge condition had higher levels of empathic concern than those in the active control and baseline control conditions. Participants in the combined knowledge condition had higher levels of personal distress than those in the active control condition and those in the baseline condition. There were no significant effects of dementia knowledge on attitudes, social comfort, or worry and fear about developing dementia.

Inconsistent with hypotheses and prior work (Ebert, McFadden, \& Kulibert, 2019; Kimzey, Smith, \& Alfred, 2016), the personhood-based knowledge intervention did not reduce personal dementia fear (RQ1, H1) or increase social comfort (RQ2, H2). These differences in findings may be in part due to the duration and intensity of interventions not being sufficient to bring about change in attitudes. While Kimzey, Smith, and Alfred (2016) found a statistically significant increase in social comfort and personhood-based knowledge amongst nursing students who worked in an immersive experience with persons with dementia, a similar change was not found in the group of nursing students who completed online educational modules. It 
may be that the present study mimicked the formatting of an online educational module and was missing aspects of a more immersive experience.

Further, attitude change literature indicates that intergroup contact may be most crucial for enduring shifts in beliefs (e.g., stereotypes) about out-groups and improving intergroup relations (Dovidio, Gaertner, \& Kawakami, 2003; Pettigrew, 1998; Pettigrew \& Tropp, 2006). Allport (1954) stipulated ideal conditions of intergroup contact being situations: (1) in which members are of equal group status, (2) promoting common goals and cooperation (3) with institutional support by authority, and (4) opportunities to disconfirm outgroup stereotypes via personal and individualized knowledge of the outgroup. Having individuals simply read information and first-hand accounts of persons with dementia may not have been sufficient to induce attitude change. In other words, in order to produce meaningful change in attitudes, people may need to interact with persons with dementia in a way that challenges stereotypes of persons with dementia and promotes cooperation, such as in an immersive experience comparable to Kimzey, Alfred, and Smith (2016). Further, some prior work on changes in dementia attitudes has revealed that when medical and/or nursing students engage in creative activities with persons with dementia, levels of social comfort and personhood-based knowledge increase over time (George, Stuckey, Dillon, \& Whitehead, 2011). This rationale may also support why the different dementia knowledge interventions did not lead to changes in explicit dementia attitudes (RQ3). In line with Wood (2000), it may be that in order to effectively promote attitude change, greater depth of processing is required as might be more likely in an immersive experience than when simply reading information on an online survey. Participants in the current study may have been more likely to engage in more shallow processing which 
typically evokes heuristics or focus on simple attributes of targets, such as stereotypes, as opposed to more effortful processing that promotes enduring change (Wood, 2000).

The fourth research question sought to explore whether different dementia knowledge interventions lead to differences in empathic concern and personal distress. Overall, there was a significant effect of experimental condition on empathic concern and personal distress. Specifically, an increase in personhood-based knowledge led to higher levels of empathic concern in comparison to the baseline control and active control conditions. It is possible that information included in the personhood-based knowledge condition changed beliefs individuals had regarding the warmth and competence of persons with dementia, leading to higher levels of empathic concern. The combination of both biomedical and personhood-based knowledge led to higher levels of personal distress than the active control and baseline control conditions. Interestingly, both biomedical knowledge and personhood-based knowledge individually produced higher levels of personal distress in comparison to the active and baseline control conditions, but not at a statistically significant level.

Of note, the biomedical knowledge condition produced significantly higher levels of negative affect than the baseline and active control conditions, while personhood-based knowledge and the combined knowledge conditions produced significantly higher levels of negative affect than all other conditions. Thus, although negative affect was controlled for in analyses, the combination of these two forms of knowledge may have instigated reactance as opposed to attitude change. This would be consistent with Leventhal's (1970) model of fear communication which explains attitude and behavior change as a mechanism of fear. This model posits that in order for communication to instigate attitude and behavior change, it must avoid 
instigating fear. In other words, the persuasive nature of the information provided by the conditions may have been undermined by the fear, or negative affect, which they instigated.

It is also possible that the manipulations themselves were not strong enough to produce enduring attitude change despite producing differences in affective states. Paired samples t-tests revealed an increase in personhood-based knowledge amongst participants in the personhoodbased and combined knowledge conditions. Similarly, paired samples t-tests revealed an increase in biomedical knowledge amongst participants in the biomedical knowledge condition, combined knowledge condition, and personhood-based knowledge condition. It should be noted that the personhood-based knowledge condition also led to significant differences in biomedical knowledge, indicating that perhaps this manipulation tapped into biomedical knowledge and not merely personhood-based knowledge alone.

Although it appears the manipulation of biomedical and personhood-based knowledge was successful across each respective condition, our results were inconsistent with our hypotheses that the manipulation of dementia knowledge would produce differences in social comfort, attitudes, dementia worry, and personal dementia fear. Although prior work indicates that individuals with higher levels of personhood-based knowledge have lower levels of personal dementia fear and higher levels of social comfort, experimental manipulation of these variables revealed no such relation. These results could be explained by (1) strength of manipulation was not enough to produce meaningful differences in level of biomedical and personhood-based knowledge, (2) dosage and/or formatting of the manipulation was not enough to produce meaningful change in attitudes, which are comprised of cognitive, affective, and behavioral components. Indeed, the manipulations did produce changes in affective states of empathic 
concern and personal distress; however, these may be more easily manipulated than explicit and implicit attitudes towards persons with dementia.

\section{Limitations and Future Directions}

A potential limitation of the present study may have been difference in length and formatting of the knowledge interventions. Although the personhood and biomedical knowledge interventions were similar in length, their content, by nature, differed drastically. Along these same lines, the combined knowledge condition was substantially longer than the individual knowledge conditions. Although the order in which the forms of knowledge presented to participants was counterbalanced in this condition, we cannot be sure that differences were due to receiving both form of knowledge versus length of the knowledge intervention.

Although exposure was dichotomized (e.g., knowing a friend/family member with dementia or not) and controlled for in the analyses, future work may want to explore the extent to which level of exposure and level of care provided to persons with dementia moderates the relation between experimental manipulation of knowledge and outcome variables associated with attitudes.

Future research could systematically explore changes in dementia attitudes and affective responses through intergroup interactions, whereby levels of dementia knowledge are repeatedly measured. Further, future work should include measures of warmth and competence in order to parse out the mechanisms of any attitude change evidenced.

\section{Implications}

The findings of the present study, in tandem with prior work, has implications for future work aimed towards improving attitudes of healthcare professionals, and laypersons, towards persons with dementia. Although knowledge interventions may increase feelings of empathic 
concern and personal distress, they may not be sufficient to produce meaningful attitude change towards persons with dementia. 


\section{References}

Allport, G.W. 1954 The nature of prejudice Cambridge, Mass., Addison-Wesley.

Alzheimer's Disease International. (2016). Dementia-friendly communities: Key principles.

Retrieved from https://www.alz.co.uk/adi/pdf/dfc-principles.pdf

Alzheimer's Society. (2007). Dementia UK: The full report. Alzheimer's Society.

Anderson, L. A., Day, K. L., Beard, R. L., Reed, P. S., \& Wu, B. (2009). The public's

perceptions about cognitive health and Alzheimer's disease among the U.S. population: A national review. The Gerontologist, 49, S3-S11.

Batson, C. D. (1998). Prosocial behavior and altruism. The Handbook of Social Psychology, 4, 282-316.

Batson, C. D. (2011). Altruism in humans. Oxford University Press, USA.

Batson, C. D., Fultz, J., \& Schoenrade, P. A. (1987). Distress and empathy: Two qualitatively distinct vicarious emotions with different motivational consequences. Journal of Personality, 55, 19-39.

Behuniak, S. M. (2011). The living dead? The construction of people with Alzheimer's disease as zombies. Ageing \& Society, 31, 70-92.

Burke, B. L., Martens, A., \& Faucher, E. H. (2010). Two decades of terror management theory: A meta-analysis of mortality salience research. Personality and Social Psychology Review, 14, 155-195.

Carpenter, B. D., Balsis, S., Otilingam, P. G., Hanson, P. K., \& Gatz, M. (2009). The Alzheimer's Disease Knowledge Scale: Development and psychometric properties. The Gerontologist, 49, 236-247. 
Connell, C. M., Roberts, J. S., \& McLaughlin, S. J. (2007). Public opinion about Alzheimer disease among blacks, hispanics, and whites: Results from a national survey. Alzheimer Disease \& Associated Disorders, 21, 232-240.

Connell, C. M., Roberts, J. S., McLaughlin, S. J., \& Akinleye, D. (2009). Racial differences in knowledge and beliefs about Alzheimer disease. Alzheimer Disease \& Associated Disorders, 23, 110-116.

Cottrell, C. A., \& Neuberg, S. L. (2005). Different emotional reactions to different groups: a sociofunctional threat-based approach to" prejudice". Journal of Personality and Social Psychology, 88, 770 .

Cuddy, A. J., Fiske, S. T., Kwan, V. S., Glick, P., Demoulin, S., Leyens, J. P., Bond, M. H., Croizet, J. C., Ellemers, N., Sleebos, E., Htun, T. T., Kim, H. J., Maio, G., Perry, J., Petkova, K., Todorov, V., Rodríguez-Bailón, R., Morales, E., Moya, M., Palacios, M., ... Ziegler, R. (2009). Stereotype content model across cultures: towards universal similarities and some differences. The British Journal of Social Psychology, 48, 1-33.

Cuddy, A. J., Fiske, S. T., \& Glick, P. (2007). The BIAS map: behaviors from intergroup affect and stereotypes. Journal of Personality and Social Psychology, 92, 631.

Cui, R., Maxfield, M., \& Fiske, A. (Under Review, 2019). Dementia-related anxiety and coping styles associated with suicidal ideation. Aging \& Mental Health, 1-4.

Dovidio, J. F., Gaertner, S. L., \& Kawakami, K. (2003). Intergroup contact: The past, present, and the future. Group Processes \& Intergroup Relations, 6, 5-21.

Dupuis, S.L., Kontos, P.C., Mitchell, G., Jonas-Simpson, C., Gray, J. (2016). Re-claiming citizenship through the arts. Dementia, 15, 358-380. 
Ebert, A. R., Kulibert, D., \& McFadden, S. H. (2019). Effects of dementia knowledge and dementia fear on comfort with people having dementia: Implications for dementiafriendly communities. Dementia.

Ebert, A. R., McFadden, S. H., \& Kulibert, D. K. (2019, in preparation). Personhood-Based Knowledge: A New Construct Predicting Personal Dementia Fear.

FIELD, A. P. (2005).Discovering statistics with SPSS (2nd ed.). London: Sage.

Fiske, S. T. (2015). Intergroup biases: A focus on stereotype content. Current Opinion in Behavioral Sciences, 3, 45-50.

Fiske, S. T., Cuddy, A. J., Glick, P., \& Xu, J. (2002). A model of (often mixed) stereotype content: competence and warmth respectively follow from perceived status and competition. Journal of Personality and Social Psychology, 82, 878.

Fiske, S. T., Xu, J., Cuddy, A., \& Glick, P. (1999). (Dis)respecting versus (dis)liking: Status and interdependence predict ambivalent stereotypes of competence and warmth. Journal of Social Issues, 55, 473-491.

French, S. L., Floyd, M., Wilkins, S., \& Osato, S. (2012). The fear of Alzheimer's disease scale: a new measure designed to assess anticipatory dementia in older adults. International Journal of Geriatric Psychiatry, 27, 521-528.

Fritsch, T., Kwak, J., Grant, S., Lang, J., Montgomery, R. R., \& Basting, A. D. (2009). Impact of TimeSlips, a creative expression intervention program, on nursing home residents with dementia and their caregivers. The Gerontologist, 49, 117-127

Geen, R. G. (1998). Processes and personal variables in affective aggression. In Human aggression (pp. 1-21). Academic Press. 
Glick, P. \& Fiske, S. T. (2001a). Ambivalent sexism. In M. P. Zanna (Ed.), Advances in experimental social psychology (Vol. 33, pp. 115-188). Thousand Oaks, CA: Academic Press.

Glick, P., \& Fiske, S. T. (2001b). Ambivalent stereotypes as legitimizing ideologies: Differentiating paternalistic and envious prejudice. In J. Jost \& B. Major (Eds.), The psychology of legitimacy (pp. 278-306). Cambridge, England: Cambridge University Press.

George, D. R., Stuckey, H. L., Dillon, C. F., \& Whitehead, M. M. (2011). Impact of participation in TimeSlips, a creative group-based storytelling program, on medical student attitudes toward persons with dementia: A qualitative study. The Gerontologist, 51, 699-703.

Greenberg, J., Pyszczynski, T., \& Solomon, S. (1986). The causes and consequences of a need for self-esteem: A terror management theory. In Public self and private self (pp. 189212). Springer, New York, NY.

Halpern, J., \& Weinstein, H. M. (2004). Rehumanizing the other: Empathy and reconciliation. Human Rights Quarterly, 26, 561.

Jackman, M. R. (2001). License to kill: Violence and legitimacy in expropriative social relations. In J. T. Jost \& B. Major (Eds.), The psychology of legitimacy: Emerging perspectives on ideology, justice, and intergroup relations (p. 437-467). Cambridge University Press.

Kaiser, F. G., \& Wilson, M. (2019). The Campbell paradigm as a behavior-predictive reinterpretation of the classical tripartite model of attitudes. European Psychologist, 24, 359-374. 
Kessler, E., Bowen, C. E., Baer, M., Froelich, L., \& Wahl, H. (2012). Dementia worry: A psychological examination of an unexpected phenomenon. European Journal of Ageing, 9, 275-284.

Kimzey, M., Smith, B. M., \& Alfred, D. (2015). The impact of educational experiences on nursing students' knowledge and attitudes toward people with Alzheimer's disease: A mixed method study, Nurse Education Today, 46, 57-63.

Kinney, J. M., Yamashita, T., \& Brown, J. S. (2017). Measuring positive attitudes toward persons with dementia: A validation of the Allophilia Scale. Dementia, 16, 1045-1060.

Kinzer, A., \& Suhr, J. A. (2016). Dementia worry and its relationship to dementia exposure, psychological factors, and subjective memory concerns. Applied Neuropsychology: Adult, 23, 196-204.

Kulibert, D., Ebert, A., Preman, S., \& McFadden, S. H. (2018). In-home use of personalized music for persons with dementia. Dementia, 18, 2971-2984.

Leventhal, H. (1970). Findings and theory in the study of fear communications. Advances in Experimental Social Psychology, 5, 119-186.

Milne, A. (2010) The 'D' word: Reflections on the relationship between stigma, discrimination and dementia. Journal of Mental Health, 19, 227-233.

Miron, A. M., McFadden, S. H., Nazario, A. S., \& Buelow, J. (2017). Perspective taking, empathic concern, and perceived humanness of people with dementia. Educational Gerontology, 43, 468-479.

Miron, A. M., Thompson, A. E., McFadden, S. H., \& Ebert, A. R. (2017). Young adults' concerns and coping strategies related to their interactions with their grandparents and great-grandparents with dementia. Dementia, 18, 1025-1041. 
Mitchell, G.J., Dupuis, S.L., Kontos, P.C. (2017). Dementia discourse: from imposed suffering to knowing otherwise. Journal of Applied Hermeneutics, 5.

McParland, P., Devine, P., Innes, A., \& Gayle, V. (2012). Dementia knowledge and attitudes of the general public in Northern Ireland: An analysis of national survey data. International Psychogeriatrics, 24, 1600.

McPherson, S., Hiskey, S., \& Alderson, Z. (2016). Distress in working on dementia wards-A threat to compassionate care: A grounded theory study. International Journal of Nursing Studies, 53, 95-104.

O’Connor, M. L., \& McFadden, S. H. (2010). Development and psychometric validation of the Dementia Attitudes Scale. International Journal of Alzheimer's Disease, 2010, 1-10.

Pasupathi, M., \& Löckenhoff, C. E. (2002). Ageist behavior. In T. D. Nelson (Ed.), Ageism: Stereotyping and prejudice against older persons (p. 201-246). The MIT Press.Pettigrew, T. F. (1998). Intergroup contact theory. Annual Review of Psychology, 49, 65-85.

Pettigrew, T. F., \& Tropp, L. R. (2006). A meta-analytic test of intergroup contact theory. Journal of Personality and Social Psychology, 90, 751.

Prince, M., Wimo, A., Guerchet, M., Ali, G. C., Wu, Y. T., \& Prina, M. (2015). The global impact of dementia. An Analysis of Prevalence, Incidence, Cost and Trends. World Alzheimer Report, 1-82.

Reed, P., Carson, J. \& Gibb, Z. (2017). Transcending the tragedy discourse of dementia; An ethical imperative for promoting selfhood, meaningful relationships, and wellbeing, $A M A$ Journal of Ethics, 19, 693-703. 
Rosenberg, M. J., Hovland, C. I., McGuire, W. J., Abelson, R. P., \& Brehm, J. W. (1960). Attitude organization and change: An analysis of consistency among attitude components.(Yales studies in attitude and communication.), Vol. III.

Suhr, J., \& Isgrigg, A. (2011). Development and Initial Validation of an Alzheimer's Disease Worry Scale. In Paper presented at the annual meeting of the International Neuropsychological Society, Boston, MA.

Swinnen, A., \& de Medeiros, K. (2017). "Play" and people living with dementia: A humanitiesbased inquiry of TimeSlips and the Alzheimer's Poetry Project. The Gerontologist, 58, 261-269.

Toye, C., Lester, L., Popescu, A., McInerney, F., Andrews, S., \& Robinson, A. L. (2014). Dementia Knowledge Assessment Tool Version Two: Development of a tool to inform preparation for care planning and delivery in families and care staff. Dementia, 13, 248256.

Watson, D., Clark, L. A., \& Tellegen, A. (1988). Development and validation of brief measures of positive and negative affect: the PANAS scales. Journal of Personality and Social Psychology, 54, 1063.

Werner, P. (2002). Assessing correlates of concern about developing Alzheimer's dementia among adults with no family history of the disease. American Journal of Alzheimer's Disease, 17, 331-337.

Werner, P. (2005). Social distance toward a person with Alzheimer's disease. International Journal of Geriatric Psychiatry, 20, 182-188.

Werner, P., \& Davidson, M. (2004). Emotional reactions of laypersons to someone with Alzheimer's disease. International Journal of Geriatric Psychiatry, 19, 391-397. 
Witte, K. (1992). Putting the fear back into fear appeals: The extended parallel process model. Communications Monographs, 59, 329-349.

Wood, W. (2000). Attitude change: Persuasion and social influence. Annual Review of Psychology, 51. 
Table 1.

Tables and Figures

Demographics by Condition

\begin{tabular}{|c|c|c|c|c|c|c|c|c|c|c|c|c|c|}
\hline & \multicolumn{2}{|c|}{ Overall } & \multicolumn{2}{|c|}{$\begin{array}{l}\text { Biomedical } \\
(N=66)\end{array}$} & \multicolumn{2}{|c|}{$\begin{array}{l}\text { Personhood } \\
(\mathrm{N}=64)\end{array}$} & \multicolumn{2}{|c|}{$\begin{array}{l}\text { Active } \\
(\mathrm{N}=68)\end{array}$} & \multicolumn{2}{|c|}{$\begin{array}{l}\text { Baseline } \\
(\mathrm{N}=65)\end{array}$} & \multicolumn{2}{|c|}{$\begin{array}{l}\text { Combined } \\
(\mathrm{N}=71)\end{array}$} & \multirow[t]{2}{*}{ Sig. } \\
\hline & $\mathrm{N}$ & $\%$ & $\mathrm{~N}$ & $\%$ & $\mathrm{~N}$ & $\%$ & $\mathrm{~N}$ & $\%$ & $\mathrm{~N}$ & $\%$ & $\mathrm{~N}$ & $\%$ & \\
\hline \multicolumn{14}{|l|}{ Education } \\
\hline GED & 10 & 2.9 & 2 & 3.0 & 4 & 6.3 & 1 & 1.5 & 1 & 1.5 & 2 & 2.8 & \multirow[t]{6}{*}{$p=.693$} \\
\hline HS & 44 & 13.2 & 6 & 9.1 & 7 & 10.9 & 10 & 14.7 & 12 & 18.5 & 9 & 12.7 & \\
\hline $\mathrm{SC}$ & 101 & 30.2 & 16 & 24.2 & 20 & 31.3 & 23 & 33.8 & 20 & 30.8 & 22 & 31.0 & \\
\hline $\mathrm{CD}$ & 136 & 40.7 & 35 & 53.0 & 25 & 39.1 & 26 & 38.2 & 22 & 33.8 & 28 & 39.4 & \\
\hline GD & 40 & 12.0 & 7 & 10.6 & 7 & 10.9 & 8 & 11.8 & 8 & 12.3 & 10 & 14.1 & \\
\hline Other & 3 & 0.89 & 0 & 0 & 1 & 1.6 & 0 & 0 & 2 & 3.1 & 0 & 0 & \\
\hline \multicolumn{14}{|l|}{ Sex } \\
\hline Male & 153 & 45.8 & 33 & 50.0 & 36 & 56.3 & 26 & 38.2 & 26 & 40.0 & 32 & 45.1 & \multirow[t]{2}{*}{$p=.243$} \\
\hline Female & 181 & 54.2 & 33 & 50.0 & 28 & 43.8 & 42 & 61.8 & 39 & 60.0 & 39 & 54.9 & \\
\hline \multicolumn{14}{|l|}{ Ethnicity } \\
\hline Black & 24 & 7.2 & 5 & 7.6 & 4 & 6.3 & 4 & 5.9 & 8 & 12.3 & 3 & 4.2 & \multirow[t]{8}{*}{$p=.446$} \\
\hline Asian & 21 & 6.3 & 5 & 7.6 & 2 & 3.1 & 3 & 4.4 & 5 & 7.7 & 6 & 8.5 & \\
\hline Caucasian & 251 & 75.1 & 55 & 83.3 & 51 & 79.7 & 52 & 76.5 & 39 & 60.0 & 54 & 76.0 & \\
\hline Hispanic & 19 & 5.7 & 0 & 0 & 5 & 7.8 & 5 & 7.4 & 7 & 10.8 & 2 & 2.8 & \\
\hline M.E. & 3 & 0.89 & 0 & 0 & 1 & 1.6 & 1 & 1.5 & 0 & 0 & 1 & 1.4 & \\
\hline Nat. Am. & 3 & 0.89 & 0 & 0 & 0 & 0 & 0 & 0 & 0 & 0 & 3 & 4.2 & \\
\hline Multi & 11 & 3.3 & 1 & 1.5 & 0 & 0 & 3 & 4.4 & 5 & 7.7 & 2 & 2.8 & \\
\hline Other & 2 & .60 & 0 & 0 & 1 & 1.6 & 0 & 0 & 1 & 1.5 & 0 & 0 & \\
\hline \multicolumn{14}{|l|}{ Exposure } \\
\hline DK & 213 & 63.8 & 37 & 56.1 & 42 & 65.6 & 42 & 61.8 & 44 & 67.7 & 48 & 67.6 & \multirow[t]{3}{*}{$p=.736$} \\
\hline $\mathrm{K}$ & 55 & 16.4 & 14 & 21.2 & 10 & 15.6 & 14 & 20.6 & 8 & 12.3 & 9 & 12.7 & \\
\hline $\mathrm{C}$ & 66 & 19.7 & 15 & 22.7 & 12 & 18.8 & 12 & 17.6 & 13 & 20.0 & 14 & 19.7 & \\
\hline
\end{tabular}


*Note. Overall = Overall Participant Sample; Combined = Combined Knowledge Condition; $\mathrm{SC}=$ Some College; CD = College Degree; GD = Graduate Degree; M.E. = Middle Eastern; Nat. Am. = Native American; Multi $=$ Multiracial; DK $=$ Do not know anyone with dementia; $\mathrm{K}=$ Know someone with dementia; $\mathrm{C}=$ Provide care for someone with dementia 
Table 2.

Means, Standard Deviations, and Ranges of Covariates and Outcome Variables by Condition

\begin{tabular}{|c|c|c|c|c|c|c|c|c|c|c|c|c|c|c|c|}
\hline & \multicolumn{3}{|c|}{$\begin{array}{l}\text { Biomedical } \\
(\mathrm{N}=66)\end{array}$} & \multicolumn{3}{|c|}{$\begin{array}{l}\text { Personhood } \\
(\mathrm{N}=64)\end{array}$} & \multicolumn{3}{|c|}{$\begin{array}{l}\text { Active } \\
(\mathrm{N}=68)\end{array}$} & \multicolumn{3}{|c|}{$\begin{array}{l}\text { Baseline } \\
(\mathrm{N}=65)\end{array}$} & \multicolumn{3}{|c|}{$\begin{array}{l}\text { Combined } \\
(\mathrm{N}=71)\end{array}$} \\
\hline & $\mathrm{M}$ & SD & Range & $\mathrm{M}$ & SD & Range & $\mathrm{M}$ & SD & Range & $\mathrm{M}$ & SD & Range & $\mathrm{M}$ & SD & Range \\
\hline DW & 1.79 & 0.86 & $\begin{array}{l}1.00- \\
4.08\end{array}$ & 2.06 & 1.02 & $\begin{array}{l}1.00- \\
4.58\end{array}$ & 1.67 & 0.76 & $\begin{array}{l}1.00- \\
4.08\end{array}$ & 1.63 & 0.77 & $\begin{array}{l}1.00- \\
4.08\end{array}$ & 1.91 & 0.90 & $\begin{array}{l}1.00- \\
4.67\end{array}$ \\
\hline Comfort & 4.45 & 1.25 & $\begin{array}{l}2.10- \\
7.00\end{array}$ & 4.60 & 1.19 & $\begin{array}{l}2.50- \\
7.00\end{array}$ & 4.61 & 1.13 & $\begin{array}{l}1.90- \\
7.00\end{array}$ & 4.64 & 1.08 & $\begin{array}{l}2.20- \\
7.00\end{array}$ & 4.67 & 1.18 & $\begin{array}{l}1.50- \\
7.00\end{array}$ \\
\hline Fear & 2.49 & 1.01 & $\begin{array}{l}1.00- \\
4.91\end{array}$ & 2.57 & 0.94 & $\begin{array}{l}1.00- \\
4.64\end{array}$ & 2.33 & 0.91 & $\begin{array}{l}1.00- \\
4.27\end{array}$ & 2.22 & 0.98 & $\begin{array}{l}1.00- \\
4.64\end{array}$ & 2.62 & 0.90 & $\begin{array}{l}1.00- \\
5.00\end{array}$ \\
\hline Attitudes & 4.08 & 1.03 & $\begin{array}{l}1.00- \\
6.00\end{array}$ & 4.29 & 0.93 & $\begin{array}{l}1.63- \\
6.00\end{array}$ & 4.16 & 0.90 & $\begin{array}{l}2.44- \\
6.00\end{array}$ & 4.08 & 0.92 & $\begin{array}{l}1.00- \\
6.00\end{array}$ & 4.32 & 1.03 & $\begin{array}{l}1.88- \\
6.00\end{array}$ \\
\hline PD & 2.01 & 1.05 & $\begin{array}{l}1.00- \\
5.00\end{array}$ & 2.06 & 0.98 & $\begin{array}{l}1.00- \\
5.00\end{array}$ & 1.34 & 0.61 & $\begin{array}{l}1.00- \\
3.20\end{array}$ & 1.48 & 0.67 & $\begin{array}{l}1.00- \\
3.40\end{array}$ & 2.05 & 0.92 & $\begin{array}{l}1.00- \\
4.60\end{array}$ \\
\hline $\mathrm{EC}$ & 3.13 & 1.08 & $\begin{array}{l}1.00- \\
5.00\end{array}$ & 3.73 & 0.92 & $\begin{array}{l}1.50- \\
5.00\end{array}$ & 2.62 & 1.19 & $\begin{array}{l}1.00- \\
5.00\end{array}$ & 2.85 & 1.20 & $\begin{array}{l}1.00- \\
5.00\end{array}$ & 3.55 & 1.09 & $\begin{array}{l}1.00- \\
5.00\end{array}$ \\
\hline PA & 2.84 & 0.80 & $\begin{array}{l}1.30- \\
5.00\end{array}$ & 3.03 & 0.76 & $\begin{array}{l}1.30- \\
4.70\end{array}$ & 3.00 & 0.89 & $\begin{array}{l}1.20- \\
5.00\end{array}$ & 3.03 & 0.97 & $\begin{array}{l}1.30- \\
5.00\end{array}$ & 2.95 & 0.75 & $\begin{array}{l}1.00- \\
4.70\end{array}$ \\
\hline NA & 1.65 & 0.73 & $\begin{array}{l}1.00- \\
3.80\end{array}$ & 1.81 & 0.84 & $\begin{array}{l}1.00- \\
3.80\end{array}$ & 1.31 & 0.65 & $\begin{array}{l}1.00- \\
3.80\end{array}$ & 1.34 & 0.63 & $\begin{array}{l}1.00- \\
3.80\end{array}$ & 1.61 & 0.63 & $\begin{array}{l}1.00- \\
3.80\end{array}$ \\
\hline PBK pre & 5.93 & 0.67 & $\begin{array}{l}3.80- \\
7.00\end{array}$ & 5.68 & 0.78 & $\begin{array}{l}3.90- \\
7.00\end{array}$ & 5.85 & 0.90 & $\begin{array}{l}1.30- \\
7.00\end{array}$ & 5.74 & 0.88 & $\begin{array}{l}1.90- \\
7.00\end{array}$ & 5.80 & 0.80 & $\begin{array}{l}3.70- \\
7.00\end{array}$ \\
\hline $\begin{array}{l}\text { PBK } \\
\text { post }\end{array}$ & 5.98 & 0.71 & $\begin{array}{l}4.00- \\
7.00\end{array}$ & 5.96 & 0.91 & $\begin{array}{l}3.80- \\
7.00\end{array}$ & 5.94 & 0.74 & $\begin{array}{l}3.40- \\
7.00\end{array}$ & 5.84 & 0.73 & $\begin{array}{l}3.40- \\
7.00\end{array}$ & 6.09 & 0.83 & $\begin{array}{l}3.50- \\
7.00\end{array}$ \\
\hline BK pre & 13.09 & 3.47 & $\begin{array}{l}5.00- \\
21.00\end{array}$ & 12.12 & 3.47 & $\begin{array}{l}3.00- \\
18.00\end{array}$ & 13.35 & 3.59 & $\begin{array}{l}0.00- \\
18.00\end{array}$ & 12.15 & 3.97 & $\begin{array}{l}4.00- \\
21.00\end{array}$ & 12.79 & 3.52 & $\begin{array}{l}0.00- \\
18.00\end{array}$ \\
\hline BK post & 15.91 & 2.82 & $\begin{array}{l}5.00- \\
20.00\end{array}$ & 12.89 & 3.43 & $\begin{array}{l}5.00- \\
19.00\end{array}$ & 13.16 & 3.28 & $\begin{array}{l}2.00- \\
19.00\end{array}$ & 12.015 & 3.86 & $\begin{array}{l}4.00- \\
20.00\end{array}$ & 15.37 & 3.55 & $\begin{array}{l}0.00- \\
20.00\end{array}$ \\
\hline Age & 42.79 & 14.57 & $21-76$ & 42.70 & 16.79 & $19-78$ & 48.26 & 17.08 & $21-76$ & 44.25 & 17.12 & $19-76$ & 44.46 & 17.02 & $20-78$ \\
\hline
\end{tabular}


Note . Combined = Combined Knowledge Condition; DW = Dementia Worry; Comfort = Social Comfort; Fear = Dementia Fear; PD = Personal Distress; EC = Empathic Concern; PA = Positive Affect; NA = Negative Affect; PBK = Personhood-based Knowledge; $\mathrm{BK}=$ Biomedical Knowledge 
Table 3.

Bivariate Correlations Among Covariates and Outcome Variables

\begin{tabular}{|c|c|c|c|c|c|c|c|c|c|c|c|c|c|}
\hline & DW & Comf & Fear & Attitudes & PD & $\mathrm{EC}$ & PA & NA & $\begin{array}{c}\text { PBK } \\
\text { pre }\end{array}$ & $\begin{array}{l}\text { PBK } \\
\text { post }\end{array}$ & $\begin{array}{l}\text { BK } \\
\text { pre }\end{array}$ & $\begin{array}{c}\text { BK } \\
\text { post }\end{array}$ & Age \\
\hline DW & 1 & & & & & & & & & & & & \\
\hline Comf & $-.131^{*}$ & 1 & & & & & & & & & & & \\
\hline Fear & $.795^{* *}$ & $-.198^{* *}$ & 1 & & & & & & & & & & \\
\hline Attitudes & 0.090 & $.747^{* *}$ & 0.041 & 1 & & & & & & & & & \\
\hline PD & $.435^{* *}$ & $-.206^{* *}$ & $.436^{* *}$ & 0.001 & 1 & & & & & & & & \\
\hline $\mathrm{EC}$ & $.157^{* *}$ & $.343^{* *}$ & $.153^{* *}$ & $.498^{* *}$ & $.333^{* *}$ & 1 & & & & & & & \\
\hline PA & 0.040 & $.383^{* *}$ & -0.056 & $.439^{* *}$ & -0.033 & $.603^{* *}$ & 1 & & & & & & \\
\hline NA & $.502^{* *}$ & $-.209^{* *}$ & $.450^{* *}$ & -0.004 & $.855^{* *}$ & $.285^{* *}$ & - & 1 & & & & & \\
\hline PBK pre & -0.086 & $.290^{* *}$ & 0.087 & $.403^{* *}$ & -0.057 & $.199^{* *}$ & $\begin{array}{c}0.031 \\
.130^{*}\end{array}$ & $-.169^{* *}$ & 1 & & & & \\
\hline PBK post & -0.099 & $.403^{* *}$ & 0.023 & $.532^{* *}$ & -0.067 & $.337^{* *}$ & $.228^{* *}$ & $-.196^{* *}$ & $.713^{* *}$ & 1 & & & \\
\hline BK pre & -0.056 & $.122^{*}$ & 0.077 & 0.068 & -0.052 & 0.065 & 0.104 & $-.126^{*}$ & $.269^{* *}$ & $.254^{* *}$ & 1 & & \\
\hline BK post & -0.008 & 0.040 & $.132^{*}$ & 0.054 & 0.080 & $.139^{*}$ & 0.065 & -0.072 & $.275^{* *}$ & $.286^{* *}$ & $.725^{* *}$ & 1 & \\
\hline Age & $-.176^{* *}$ & $.166^{* *}$ & -0.098 & -0.012 & $-.129^{*}$ & 0.076 & $.183^{* *}$ & $-.196^{* *}$ & 0.015 & 0.059 & $.239^{* *}$ & $.203^{* *}$ & 1 \\
\hline
\end{tabular}

Note. ${ }^{*} \mathrm{p}<0.05 ; * * \mathrm{p}<.01 ; \mathrm{DW}=$ Dementia Worry; Comf $=$ Social Comfort; Fear = Dementia Fear; PD = Personal Distress; EC =

Empathic Concern; PA = Positive Affect; NA = Negative Affect; PBK = Personhood-based Knowledge; BK = Biomedical Knowledge 
Table 4.

Analysis of Covariance: Dementia Worry by Condition

\begin{tabular}{lllll}
\hline Source & $\mathrm{F}$ & $\mathrm{df}$ & $\mathrm{p}$ & Partial eta squared \\
\hline Condition & 0.737 & 4,324 & 0.567 & 0.009 \\
Intercept & 147.040 & & 0.000 & 0.312 \\
Exposure & 0.638 & & 0.425 & 0.002 \\
Interest & 2.335 & & 0.127 & 0.007 \\
Age & 5.793 & & 0.017 & 0.018 \\
Sex & 0.503 & & 0.479 & 0.002 \\
Neg. Aff. & 80.283 & & 0.000 & 0.199 \\
\hline
\end{tabular}

Note . Condition $=$ Experimental Condition; Exposure $=$ Dementia Exposure $;$ Neg. Aff. $=$ Negative Affect 
Table 5.

Analysis of Covariance: Social Comfort by Condition

\begin{tabular}{lllll}
\hline Source & $\mathrm{F}$ & $\mathrm{df}$ & $\mathrm{p}$ & Partial eta squared \\
\hline Condition & 0.344 & 4,334 & 0.848 & 0.004 \\
& & & & \\
Intercept & 30.712 & & 0.000 & 0.087 \\
Exposure & 5.362 & & 0.021 & 0.016 \\
Interest & 34.691 & & 0.000 & 0.097 \\
Age & 0.107 & & 0.744 & 0.000 \\
Sex & 2.292 & & 0.131 & 0.007 \\
Neg. Aff. & 19.434 & & 0.000 & 0.057 \\
\hline
\end{tabular}

Note. Condition $=$ Experimental Condition; Exposure $=$ Dementia Exposure $;$ Neg. Aff. $=$ Negative Affect 
Table 6.

Analysis of Covariance: Dementia Fear by Condition

\begin{tabular}{lllll}
\hline Source & $\mathrm{F}$ & $\mathrm{df}$ & $\mathrm{p}$ & Partial eta squared \\
\hline Condition & 0.626 & 4,334 & .644 & .008 \\
Intercept & 124.488 & & 0.000 & 0.354 \\
Exposure & 1.626 & & 0.128 & 0.007 \\
Interest & 0.729 & & 0.308 & 0.003 \\
Age & 0.777 & & 0.293 & 0.003 \\
Sex & 0.743 & & 0.304 & 0.003 \\
Neg. Aff. & 58.494 & & 0.000 & 0.205 \\
\hline
\end{tabular}

Note. Condition $=$ Experimental Condition; Exposure $=$ Dementia Exposure N Neg. Aff. $=$ Negative Affect 
Table 7.

Analysis of Covariance: Dementia Attitudes by Condition

\begin{tabular}{lllll}
\hline Source & $\mathrm{F}$ & $\mathrm{df}$ & $\mathrm{p}$ & Partial eta squared \\
\hline Condition & 0.992 & 4,334 & .412 & .012 \\
Intercept & 72.310 & & 0.000 & 0.182 \\
Exposure & 7.107 & & 0.008 & 0.021 \\
Interest & 83.417 & & 0.000 & 0.205 \\
Age & 10.509 & & 0.001 & 0.031 \\
Sex & 5.893 & & 0.016 & 0.018 \\
Neg. Aff. & 0.807 & & 0.370 & 0.002 \\
\hline
\end{tabular}

Note . Condition $=$ Experimental Condition; Exposure $=$ Dementia Exposure $;$ Neg. Aff. $=$ Negative Affect 
Table 8.

Analysis of Covariance :Empathic Concern by Condition

\begin{tabular}{lllll}
\hline Source & $\mathrm{F}$ & $\mathrm{df}$ & $\mathrm{p}$ & Partial eta squared \\
\hline Condition & 3.197 & 4,334 & 0.014 & .038 \\
& & & & \\
Intercept & 115.962 & & 0.000 & 0.264 \\
Exposure & 0.006 & & 0.936 & 0.000 \\
Interest & 105.676 & & 0.000 & 0.246 \\
Age & 0.050 & & 0.822 & 0.000 \\
Sex & 0.159 & & 0.690 & 0.000 \\
Neg. Aff. & 24.868 & & 0.000 & 0.071 \\
\hline
\end{tabular}

Note. Condition $=$ Experimental Condition; Exposure $=$ Dementia Exposure $;$ Neg. Aff. $=$ Negative Affect 
Table 9.

Analysis of Covariance: Personal Distress by Condition

\begin{tabular}{lllll}
\hline Source & $\mathrm{F}$ & $\mathrm{df}$ & $\mathrm{p}$ & Partial eta squared \\
\hline Condition & 5.036 & 4,334 & .001 & 0.059 \\
Intercept & 0.115 & & 0.734 & 0.000 \\
Exposure & 0.001 & & 0.970 & 0.000 \\
Interest & 4.489 & & 0.035 & 0.014 \\
Age & 1.201 & & 0.274 & 0.004 \\
Sex & 0.186 & & 0.667 & 0.001 \\
Neg. Aff. & 1057.004 & & 0.000 & 0.765 \\
\hline
\end{tabular}

Note . Condition $=$ Experimental Condition; Exposure $=$ Dementia Exposure $;$ Neg. Aff. $=$ Negative Affect 
Table 10.

Empathic Concern by Condition: Bonferroni Post-Hoc

\begin{tabular}{llll}
\hline Condition (I) & $(\mathrm{J})$ & $\begin{array}{l}\text { Mean Difference } \\
(\mathrm{I}-\mathrm{J})\end{array}$ & $\mathrm{p}$ \\
\hline Biomedical & Personhood & 0.069 & 0.280 \\
& Active & -0.034 & 1.000 \\
& Baseline & -0.025 & 1.000 \\
Personhood & Combined & 0.028 & 1.000 \\
& Biomedical & -0.069 & 0.280 \\
& Active & $-.102^{*}$ & 0.018 \\
Active & Baseline & $-.093^{*}$ & 0.040 \\
& Combined & -0.041 & 1.000 \\
& Biomedical & 0.034 & 1.000 \\
& Personhood & $.102^{*}$ & 0.018 \\
Baseline & Control & 0.009 & 1.000 \\
& Combined & 0.062 & 0.496 \\
& Biomedical & 0.025 & 1.000 \\
& Personhood & $.093^{*}$ & 0.040 \\
& Active & -0.009 & 1.000 \\
Combined & Combined & 0.053 & 0.904 \\
& Biomedical & -0.028 & 1.000 \\
& Personhood & 0.041 & 1.000 \\
& Vision & -0.062 & 0.496 \\
& Control & -0.053 & 0.904 \\
\hline
\end{tabular}

Note. The variable was transformed using the inverse transformation, thus differences should be inversed 
Table 11.

Personal Distress by Condition: Bonferroni Post-Hoc

\begin{tabular}{llll}
\hline Condition (I) & $(\mathrm{J})$ & $\begin{array}{l}\text { Mean Difference } \\
(\mathrm{I}-\mathrm{J})\end{array}$ & $\mathrm{p}$ \\
\hline Biomedical & Personhood & -0.011 & 1.000 \\
& Active & -0.056 & 0.118 \\
& Baseline & -0.022 & 1.000 \\
Personhood & Combined & 0.040 & 0.619 \\
& Biomedical & 0.011 & 1.000 \\
& Active & -0.044 & 0.518 \\
& Baseline & -0.011 & 1.000 \\
Active & Combined & 0.051 & 0.170 \\
& Biomedical & 0.056 & 0.118 \\
& Personhood & 0.044 & 0.518 \\
Baseline & Control & 0.033 & 1.000 \\
& Combined & $.095^{*}$ & 0.000 \\
& Biomedical & 0.022 & 1.000 \\
& Personhood & 0.011 & 1.000 \\
& Active & -0.033 & 1.000 \\
Combined & Combined & $.062^{*}$ & 0.044 \\
& Biomedical & -0.040 & 0.619 \\
& Personhood & -0.051 & 0.170 \\
& Vision & $-.095^{*}$ & 0.000 \\
& Control & $-.062^{*}$ & 0.044 \\
\hline
\end{tabular}

Note. The variable was transformed using the inverse transformation, thus differences should be inversed 


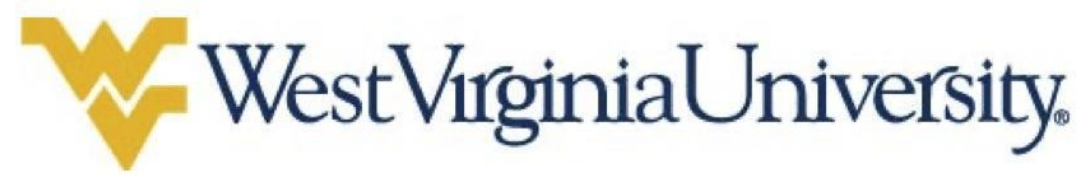

\section{Key Information for: Thoughts and Feelings About Dementia}

We are asking you to choose whether or not to volunteer in the research described below. This page provides key information that may help you to make this decision; more detailed information can be found after this section.

\section{Why is this research being done and what is involved?}

The purpose of this study is to understand how people think and feel about people with dementia. This study involves filling out questionnaires and will take approximately 40 minutes for you to complete. You will be asked to fill out a questionnaire about your mood, as well as what you think about dementia. You do not have to answer all the questions.

\section{Do I have to participate and what are the risks?}

Participation in this research study is completely voluntary and you are free to withdraw from the research at any time. You may not receive any direct benefit from this study. The knowledge gained from this study may eventually benefit others. There are no known or expected risks from participating in this study, except for the mild frustration associated with answering the questions.

\section{Who can I talk to if I have questions or concerns?}

If you have any questions or concerns about this research, you can contact Dr. Amy Fiske at (304)-2931708 from the Dept. of Psychology at West Virginia University.

For more information, please see the Cover Letter. 


\title{
WestVrrginiaUniversity.
}

Research Cover Letter

(Version date December 20, 2018)

\author{
Principal Investigator (PI) | Dr. Amy Fiske \\ PI Department | Psychology \\ Co-Investigator(s) | Alexandria R. Ebert and Maya Huggins \\ Funding Source | Department of Psychology \\ WVU IRB Protocol \# | 1904549030 \\ Title | Thoughts and Feelings About Dementia
}

\section{Contact Persons}

If you have any questions, concerns, or complaints about this research, you can contact Dr. Amy Fiske at (304)-293-1708.

For information regarding your rights as a person in research or to talk about the research, contact the WVU Human Research Protection Program (HRPP) at (304) 293-7073 or by email at IRB@mail.wvu.edu.

West Virginia University Institutional Review Board Approval of this project is on file.

\section{Introduction}

You have been asked to participate in this research study, which has been explained to you by Alexandria Ebert. This research is being conducted to fulfill the requirements for a Master of Science in Psychology from the Department of Psychology at West Virginia University. This research is being conducted by Alexandria R. Ebert, M. S., under the supervision of Dr. Amy Fiske. Funding for this research is provided by the Department of Psychology.

\section{Purpose}

The purpose of this study is to understand how people think and feel about persons with dementia. WVU expects to enroll approximately 300 subjects through Amazon's Mechanical Turk (MTURK). A total of approximately of 300 subjects from MTURK are expected to participate in this study.

\section{Description of Procedures}

This study involves reading information and filling out questionnaires and will take approximately 40 minutes for you to complete. You will be asked to fill out a questionnaire about your mood, as well as what you think about dementia. You do not have to answer all the questions.

Page 1 of 7 


\title{
Appendix A: Cover Letter and Consent Questions (cont.)
}

\section{W. WestVrrginiaUniversity.}

\section{Risks and Discomforts}

There are no known or expected risks from participating in this study, except for the mild frustration associated with answering the questions.

\author{
Alternative \\ The alternative is not to participate in the study.

\section{Benefits} \\ You may not receive any direct benefit from this study. The information gained from this study may \\ eventually benefit others.
}

\section{Financial Considerations}

You will be paid $\$ 4$. You can earn up to $\$ 4$.

Your information may be provided to the appropriate parties for billing and/or payment purposes. Please be advised that any compensation received for participation in a research study, including a gift card, is considered taxable income and must be reported to the IRS. If you are a WVU employee or a WVU student-employee, you are required to report the total amount of compensation received for your participation in a research study to the WVU Tax Services Office upon receipt of payment.

Your data and all other information related to this research study may contribute to a new discovery or treatment. In some instances, your data may be of commercial value and may be sold, patented, or licensed by the investigators and West Virginia University for use in other research or the development of new products. You will not retain any property rights nor will you share in any money that the investigators, West Virginia University, or their agents may realize.

\section{Confidentiality}

Any information about you that is obtained as a result of your participation in this research will be kept as confidential as legally possible. Your research records and test results, just like hospital records, may be subpoenaed by court order or may be inspected by the study sponsor or federal regulatory authorities without your additional consent.

In any publications that result from this research, neither your name nor any information from which you might be identified will be published without your consent.

\section{Voluntary Participation}

Participation in this study is voluntary. You are free to withdraw your consent to participate in this study at any time and there will be no penalty to you. You are also free to skip any questions you do not want to answer.

Refusal to participate or your decision to stop participating will not affect your future care at West Virginia University.

In the event new information becomes available that may affect your willingness to participate in this study, this information will be given to you so that you can make an informed decision about whether or not to continue your participation.

Page 2 of 7 
Appendix A: Cover Letter and Consent Questions (cont.)

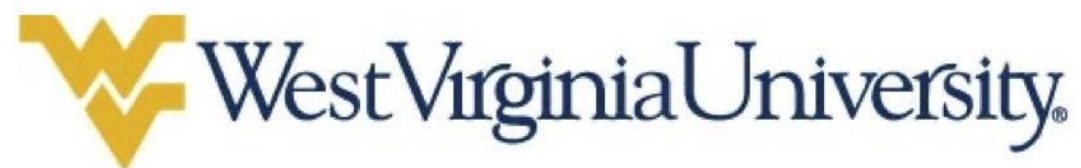

By continuing on to the next page, you are indicating your willing and voluntary consent to participate in this research.

Page 3 of 7 


\section{Appendix A: Cover Letter and Consent Questions (cont.)}

Do you willingly agree to participate in the study? (If you select yes, you are indicating that you willingly agree and will advance to the next part of the study. If you select no, you will be exited out and will not be able to complete the study.)

- Yes, I willingly agree to participate in the study.

- $\quad$ No, I do not willingly agree to participate in the study. 


\section{Appendix B: Biomedical Knowledge Pre/Post-Test}

Instructions: Please check the box that indicates your beliefs about the following statements.

\begin{tabular}{|c|c|c|c|}
\hline & $\begin{array}{c}\text { Yes, I } \\
\text { believe this }\end{array}$ & $\begin{array}{l}\text { No, I don't } \\
\text { believe this }\end{array}$ & Unsure \\
\hline $\begin{array}{l}\text { 1. Scientists are on the brink of making significant advances } \\
\text { in their understanding of dementia }\end{array}$ & & & \\
\hline 2. A cure will be found for dementia in my lifetime & & & \\
\hline 3. Dementia occurs because of changes in the brain & & & \\
\hline 4. Brain changes causing dementia are often progressive & & & \\
\hline 5. Alzheimer's disease is the main cause of dementia & & & \\
\hline 6. Blood vessel disease can also cause dementia & & & \\
\hline $\begin{array}{l}\text { 7. Confusion in an older person is almost always due to } \\
\text { dementia }\end{array}$ & & & \\
\hline 8. Only older adults develop dementia & & & \\
\hline $\begin{array}{l}\text { 9. Knowing the likely cause of dementia can help to predict } \\
\text { its progression }\end{array}$ & & & \\
\hline 10. Incontinence always occurs in the early stages of dementia & & & \\
\hline 11. Dementia is likely to limit life expectancy & & & \\
\hline $\begin{array}{l}\text { 12. Sudden increases in confusion are characteristic of } \\
\text { dementia }\end{array}$ & & & \\
\hline 13. Difficulty swallowing occurs in late stage dementia & & & \\
\hline $\begin{array}{l}\text { 14. Movement (e.g., walking, moving in a bed or chair) is } \\
\text { limited in late stage dementia }\end{array}$ & & & \\
\hline 15. Dementia is a disease of the brain & & & \\
\hline 16. Dementia is a mental illness & & & \\
\hline 17. Dementia is part of the normal aging process & & & \\
\hline 18. Dementia is another term for $\mathrm{Al}$ & & & \\
\hline
\end{tabular}




\begin{tabular}{|l|l|l|l|}
\hline $\begin{array}{l}\text { 19. Eating healthy and exercising regularly reduces the risk of } \\
\text { dementia }\end{array}$ & & & \\
\hline 20. There are drug treatments that help with dementia & & & \\
\hline 21. There are many different kinds of dementia & & & \\
\hline 22. Dementia can be cured & & & \\
\hline
\end{tabular}




\section{Appendix C: Personhood-based Knowledge Pre/Post-Test}

Directions: Please rate each statement according to how much you agree or disagree with it by circling the number that indicates your answer.

\begin{tabular}{|c|c|c|c|c|c|c|c|}
\hline & 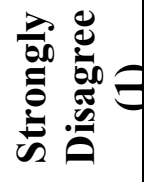 & 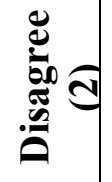 & 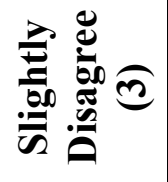 & 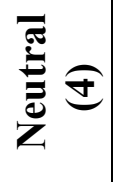 & 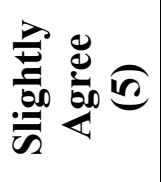 & $\overbrace{\infty}^{\infty} \Theta$ & 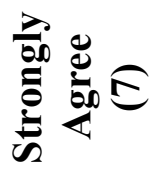 \\
\hline $\begin{array}{l}\text { 1. People with dementia can be } \\
\text { creative. }\end{array}$ & 1 & 2 & 3 & 4 & 5 & 6 & 7 \\
\hline $\begin{array}{l}\text { 2. Every person with dementia has } \\
\text { different needs. }\end{array}$ & 1 & 2 & 3 & 4 & 5 & 6 & 7 \\
\hline $\begin{array}{l}\text { 3. People with dementia like having } \\
\text { familiar things nearby. }\end{array}$ & 1 & 2 & 3 & 4 & 5 & 6 & 7 \\
\hline $\begin{array}{l}\text { 4. It is important to know the past } \\
\text { history of people with dementia. }\end{array}$ & 1 & 2 & 3 & 4 & 5 & 6 & 7 \\
\hline $\begin{array}{l}\text { 5. It is possible to enjoy interacting } \\
\text { with people with dementia. }\end{array}$ & 1 & 2 & 3 & 4 & 5 & 6 & 7 \\
\hline 6. People with dementia can enjoy life. & 1 & 2 & 3 & 4 & 5 & 6 & 7 \\
\hline $\begin{array}{l}\text { 7. People with dementia can feel when } \\
\text { others are kind to them. }\end{array}$ & 1 & 2 & 3 & 4 & 5 & 6 & 7 \\
\hline $\begin{array}{l}\text { 8. I admire the coping skills of people } \\
\text { with dementia. }\end{array}$ & 1 & 2 & 3 & 4 & 5 & 6 & 7 \\
\hline $\begin{array}{l}\text { 9. We can do a lot now to improve the } \\
\text { lives of people with dementia. }\end{array}$ & 1 & 2 & 3 & 4 & 5 & 6 & 7 \\
\hline $\begin{array}{l}\text { 10. Difficult behaviors may be a form of } \\
\text { communication for people with } \\
\text { dementia. }\end{array}$ & 1 & 2 & 3 & 4 & 5 & 6 & 7 \\
\hline
\end{tabular}




\section{$\underline{\text { Appendix D: Knowledge Interventions (Biomedical Knowledge) }}$}

\section{Overview of Dementia and Symptoms:}

Dementia is an umbrella term that points to many specific diagnoses, which differ in symptoms, progression, and cause. The most common causes of dementia are Alzheimer's disease, Vascular Cognitive Impairment, and Dementia with Lewy Bodies. A person may have just one or multiple causes. For most causes of dementia, risk increases with age. Dementia typically affects adults aged 65 and older, although early-onset dementia can affect adults as early as ages 30-50. Approximately 7 million Americans and 50 million people worldwide are living with dementia. These numbers are expected to double by 2050 .

Alzheimer's Disease and Dementia with Lewy Bodies usually begin slowly and people with these conditions experience a gradual, steady decline. Vascular Cognitive Impairment, on the other hand, may have either a sudden or a gradual beginning. The earlier the age an individual begins showing symptoms of dementia, the higher the risk for death (the shorter the life expectancy).

\section{Dementia is often classified in three stages based on severity of symptoms. Below are the three stages of dementia. Persons with dementia do not necessarily demonstrate all of these symptoms, but a combination of them.}

- Stage 1 (Mild): A person with mild dementia has some memory loss for recent events that can interfere with how well they perform everyday activities, like cooking or running errands. At this stage, a person can still be social and talk with others, although they may have difficulty understanding time and how to get to certain places. Similarly, a person may have some issues solving problems and need help staying involved in community activities such as shopping, working, and volunteering. A person might also have difficulty performing chores at home and keeping up with hobbies that are more complicated. Although a person in this stage can take care of themselves (e.g., bathing, dressing), they may need some prompting to do so.

- Stage 2 (Moderate): A person with moderate dementia has more severe memory loss, usually remembering only information that they learned years ago. A person in this stage may forget new information more rapidly. They may also have more difficulties knowing what day or time it is and knowing where they are. Similarly, a person in this stage may have difficulty handling social situations, such as when conversing with others. They might also experience severe issues with problem solving. A person might also have a hard time staying involved in community activities, even with help from others. Usually, a person in this stage is only able to perform simple chores. The person may also have lost the ability to engage in complicated interests/activities. Finally, a person in this stage will require help getting dressed and doing other personal hygiene tasks.

- $\quad$ Stage 3 (Severe): A person with severe dementia generally has severe memory loss. Specifically, this person would have a hard time remembering both recent events and things they learned years ago. A person in this stage usually understands who they are, but has a hard time knowing where they are (location), or what day or time it is, and they may not recognize people they should know. A person in this stage may lose ability to make decisions or solve problems. A 
person with severe dementia may also be too impaired to engage in any community activities or leave their home or long-term care facility. The person would have difficulty performing chores and would require extensive help taking care of themselves. They may also exhibit neuropsychiatric symptoms of dementia, which are behaviors that challenge formal or informal caregivers. These behaviors may include agitation, wandering, and aggression.

\section{Causes of Dementia:}

Alzheimer's disease is thought to be caused by a gradual build-up of amyloid plaques and neurofibrillary tangles. These are proteins in the brain that cause disruption within neurons. When this happens, brain cells die and the brain shrinks. Similarly, Dementia with Lewy Bodies is thought to be caused by a gradual build-up of Lewy Bodies in the cortical area of the brain. The cortical area of the brain is responsible for higher-order thinking (like making plans or decisions). Vascular Cognitive Impairment is generally caused by brain damage from either one or many strokes, or vascular damage.

\section{Risk and Protective Factors for Dementia:}

The main risk factors for Alzheimer's disease are age and family history. After age 60, risk doubles approximately every five years. Having a relative with Alzheimer's disease approximately doubles one's risk. The main risk factors for vascular cognitive impairment are the same risk factors that are described for stroke, such as high blood pressure. Risk factors for dementia with lewy bodies are less well studied but include age and family history. People who are more physically active seem to be less likely to develop dementia. People who eat a Mediterranean diet also seem to have a lower risk of developing Alzheimer's disease. A Mediterranean diet consists of eating mostly vegetables, fruits, grains, and healthy fats, and eating moderate amounts of dairy and small amounts of red meat.

People who have fewer years of formal education may have a higher risk for developing dementia than people with greater years of formal education. Similarly, people who have suffered a head trauma that caused them to lose consciousness may also be at a higher risk for developing dementia. On the other hand, having social support and engaging in cognitively challenging leisure activities have been associated with reduced risk for developing dementia.

Diagnosing Dementia: Generally, the assessment process for determining if someone has dementia involve doctors, who:

1. Get an extensive history of health, memory, and cognitive impairment from the patient, a close friend or family member. They will also get information about their ability to carry out daily activities.

2. Administer neuropsychological and interview-based tests of performance to determine the severity and type of cognitive impairments.

3. Perform lab tests as well as using brain imaging techniques (CT, MRI, and PET) to rule out other diagnoses.

\section{Treating Dementia:}

Some symptoms of dementia can be temporarily treated, but dementia cannot be cured at this time. Medicine and/or psychological interventions have not been proven to reverse or stop dementia from getting worse. That being said, psychosocial and environmental interventions 
(like education for caregivers on how to help someone with dementia, psychotherapy, and music therapy) show promise as a safer alternative to pharmacological interventions. Although there is some evidence that they may be effective, there are not many rigorous randomized controlled trials examining how effective they are. That being said, there have been numerous randomized controlled trials for caregivers of people with dementia.

If a person is experiencing neuropsychiatric symptoms of dementia, which are behaviors that challenge formal or informal caregivers (like aggression, wandering, agitation, acting inappropriately), behavior management programs can be very helpful. In addition, care providers might prescribe antipsychotic drugs. But, research demonstrates that these drugs are not effective and have severe side effects (like increased risk for death).

Similarly, some medications (like cholinesterase inhibitors, such as Aricept) can help people with mild to moderate Alzheimer's disease and Lewy Body Dementia have small improvements in their overall cognitive functioning, activities of daily living (such as eating, bathing, toileting, dressing), and behavior that is challenging to care-partners. Other medications (like Memantine), can help people with moderate to severe Alzheimer's disease and Lewy Body Dementia have small improvements in cognitive functioning and functional activities for a short period of time.

Cognitive stimulation (like doing things that challenge our thinking and memory) can help people with mild to moderate dementia improve their memory and functioning, although this effect is small and not yet well supported. Good cardiovascular management may help slow down the progression of dementia caused by vascular cognitive impairment. 


\section{Appendix E: Knowledge Interventions (Personhood-based Knowledge)}

"I would love to see some people with Alzheimer's not trying to stay in the shadows all the time but to say, damn it, we're people too. And we want to be talked to and respected as if we were honest to God real people." (Cary S. Henderson)

The following are first-hand accounts of persons with dementia regarding what their lives were like after their dementia symptoms began to show and progress. Dementia is an umbrella term that refers to many different causes. The most common causes of dementia are Alzheimer's disease, Vascular Cognitive Impairment, and Dementia with Lewy Bodies.

Cary S. Henderson audio recorded himself each day to provide insight on living with dementia. His wife and daughter then wrote down his audio recordings and organized them into a book, Partial View. He was 68 years old when the book was written and had a diagnosis of Alzheimer's disease.

Christine Bryden wrote her book, Dancing with Dementia. She was 56 years old when the book was written and has a diagnosis of early onset Frontotemporal Dementia. Christine Bryden also included a quote from her friend, Morris, who also had a dementia diagnosis.

Helga Rohra had an assistant writer that used her verbal explanations and hand-written notes to write her book, Dementia Activist. She was 58 years old when the book was written and had a diagnosis of early onset Dementia with Lewy Bodies.

\section{On the following pages are quotes taken from books written by or on behalf of these individuals.}

\section{Acknowledging what is lost and what still remains:}

"I guess probably the best thing that ever happened to me was while I was with Alzheimer's is that my speech has not been impeded - it's still pretty good. I may not know all the time what I'm talking about, but I, damn it, still I can talk" (Cary S. Henderson)

"There are things I wish I could do, but on the other side, there are still things that I can do and I plan to hold on to them as long as I possibly can. Laughing is absolutely wonderful. A sense of humor is probably the most important valuable thing you can have when you have Alzheimer's" (Cary S. Henderson)

"The first signs of dementia are very gradual changes in ourselves, so that we hardly notice it. Our family and friends might think 'we are not ourselves,' and we might think we are just stressed. But it is the beginning of a long slow journey of change. I felt foggy in my head and became more readily confused. [...] I was so stressed out by ordinary things and was getting terrible migraines every week. I would forget things in mid-sentence, get confused about finding my way to work, and found it increasingly difficult to make decisions. Everything was an effort and something felt very wrong!" (Christine Bryden) 
"We feel as if we are hanging onto a high cliff, above a lurking black hole. [...] Everything is as if we are first learning. Cooking burns, ironing is forgotten, washing is no longer sorted, and driving becomes scary. You tell us that we have asked you that question before, but we have no recollection. It is just a blank for the past, and this feels strange and scary, and yet you are frustrated with us." (Christine Bryden)

\section{Acceptance and coping with dementia:}

"I don't think I'm trapped any longer, like I did at first, and I feel like I can cope with it... it's kinda hard though. Somehow I learned to cope with it, mainly through - first of all, you know you're going to screw up a good many times, so just don't let it bother you. [...] When I was first diagnosed, she and I were just absolutely sure that everything was over, that life was just simply going to pot. It's difficult, I think, for somebody with Alzheimer's to not just give up and say, the hell with it. I periodically do that, but then again, there are some things that I really enjoy." (Cary S. Henderson)

"It took me three years before I could speak openly about my diagnosis. [...] Climbing back from this pit of despair had been a struggle, one in which my faith had sustained me, as well as the prayers of my friends. It was all too easy to believe the stereotype of dementia, of the late stages of the disease, of being unable to recognize anyone and of being unable to speak.[...] No one seemed to talk about the long journey beforehand between diagnosis and the end stage - the journey of living with dementia each day." (Christine Bryden)

"If you yourself are living with dementia, or notice symptoms in yourself that could be a sign of it, then I would like to share this with you: dementia is not the end! Even with dementia you can have a life of fulfillment, if you come to terms with the disability. I'm not going to paint a rosy picture. Dementia is not child's play and will challenge you every day anew. But one can live with it. Believe me." (Helga Rohra)

\section{Appreciation of caregivers and companionship:}

"My wife is trying extra hard to make things tolerable for me - to give me things to do and make me feel good. I really, really do appreciate that. If you're going to get Alzheimer's, by all means, pick out a good caregiver as they call these people, like my wonderful wife, and it's about the best you can do." (Cary S. Henderson)

"I sort of think that anybody with Alzheimer's could benefit by a friendly little dog. Somebody they can play with and talk to - it's kinda nice to talk to a dog that you know is not going to talk back. And you can't make a mistake that way. [...] She doesn't talk, she doesn't remember things, but I love her anyhow. She gives me a lot of fun just watching her. She's just a companion who is always there." (Cary S. Henderson)

"It was wonderful to get emails regularly from friends in the USA and in Canada who also had a diagnosis of dementia, and yet like me were still able to communicate, willing to speak and to challenge the accepted view of the late stages of the disease. Most of us were taking antidementia drugs, and we were not willing to accept being categorized into a medical model of decline according to set stages." (Christine Bryden) 


\section{Times of fear and frustration:}

"I remember the university of - somewhere - hospital, I got so agitated that they had to strap me down. Oh God, did I hate that. I got so excited and so mad that I think I may have even hurt myself. I was kicking and screaming. I was doing everything wrong. It's hard when you're going through all this, especially if they don't communicate with you. They didn't do a good job of explaining what they were supposed to be doing, and doing it gently. [...]And I remember that night as one of the very worst nights in all the time I've lived." (Cary S. Henderson)

"All that is given to persons with dementia is 'hospice in slow motion.' We reject this. There is life after a diagnosis of dementia, for both ourselves and our families. The toxic lie is that our abnormal brains make us biologically inferior. [...] We need to live in contradiction to the lie of dementia. [...]We can discover ways of participating in life through giving and care, which restore our sense of value and meaning. Thus strengthened we find that again we can face and surmount challenges, and affirm our courage and dignity." (Morris)

\section{Enjoying aspects of everyday life:}

"The only real constant friend I've got is music. I don't have to worry too much - I just turn on the radio and - thank goodness I know how to turn the radio on -- and turn it off - I'm not sure about turning it off. But I can turn it on." [...] "I can just listen to music and feel that I'm doing something that I just love to do. I can't make music anymore, but I can certainly use it for my own intentions - which are just to be beautiful." (Cary S. Henderson)

"I still pick up leaves, probably the same ones I had before. I love the fall colors. I pick 'em up anyhow, whether I have them or not. Every year it seems like they're prettier and prettier. I appreciate them a lot more now than I did a few years ago.” (Cary S. Henderson) 


\section{Appendix F: Active Control Condition}

\section{Overview of Vision Impairment and Symptoms:}

Visual impairment may impact vision to various degrees. Impact on vision could range from low (poor) vision to complete blindness. Common forms of visual impairment are near-sightedness, far-sightedness, and blindness. People with some vision loss often have low vision, which is a condition caused by eye disease. A person with low vision have a visual acuity (a number that identifies how clear and sharp one's vision is) of 20/70 or poorer. Globally, at least 2.2 billion people live with vision impairment. The majority of people with vision impairment are over the age of 50 years old.

Visual impairment can be present from birth or develop over the span of a person's lifetime. Vision impairment is often classified in several stages based on visual acuity. Below are the stages of vision impairment. Access to vision aids (like glasses, contact lenses, or white canes) and early-life intervention programs make vision impairment experiences different for each person.

- $\quad$ Mild: People with mild visual impairment have a visual acuity between 20/30 and 20/60. People with mild visual impairment have nearly normal vision.

- Moderate: People with moderate visual impairment have a visual acuity between 20/70 and 20/160. People with moderate visual impairment may have difficulties with normal daily activities such as driving, reading, socializing, and walking.

- Severe: People with severe visual impairment have a visual acuity between $20 / 200$ and 20/400. This is termed profound vision loss, and an individual is deemed "legally blind". People who are legally blind will have moderate difficulties with normal daily activities such as driving, reading, socializing, and walking.

- Near-total visual impairment and No Light Perception: People with near-total visual impairment or blindness have a visual acuity of 20/1,000. People with No Light Perception blindness are unable to perceive light and have an unspecified visual acuity." Only about 15\% of individuals with eye disorders are totally blind. People who have near-total or no light perception will have severe difficulties with normal daily activities such as driving, reading, socializing, and walking.

\section{Causes of Visual Impairment:}

Often, visual impairment is age-related and can be caused by cataracts, glaucoma, or macular degeneration. Cataracts are cloudy or opaque areas in the eye that can fog vision. Glaucoma includes a group of eye diseases that damage the optic nerve (associated with vision) and cause blind spots in peripheral vision. Macular degeneration is the result of damage to the part of the retina that focuses images and is the leading cause of vision loss in people over the age of 50 .

\section{Risk and Protective Factors for Vision Impairment:}


Common risk factors for vision impairment include uncorrected refractive errors, cataracts, agerelated macular degeneration, glaucoma, diabetic retinopathy, corneal opacity, and trachoma.

Uncorrected refractive errors include near-sightedness, far-sightedness, and astigmatism.

Diabetic retinopathy occurs through a diabetes complication that can affect the eyes with damage to blood tissue at the retina. When the cornea, or the transparent structure in front of the eyeball, becomes scarred, this is a corneal opacity, and it causes the cornea to appear white or clouded over. Trachoma is a contagious bacterial infection of the eye that can cause inflammation of the eye, eyelid scarring, ingrown eyelashes, and clouding in the cornea.

These causes can vary across regions due to the differences in overall income or accessibility to adequate vision treatment. Other risk factors that have been associated with eye diseases are aging, smoking, ultraviolet light exposure, and physical trauma.

Leading causes of blindness in adults are typically related to genetic factors. More than $60 \%$ of blindness cases in infants are due to congenital eye diseases. Researchers of vision impairment have been able to identify specific genes related to the development of eye diseases in recent years. The development of more common vision problems, such as lazy eye, cross-eyes, nearsightedness, and farsightedness, can also be determined through genetics. If more serious eye diseases (like blindness, glaucoma, or cataracts) are common in a person's family, early intervention can be beneficial.

A person can reduce their risk for vision impairment by engaging in healthy lifestyle behaviors. Specific behaviors include eating foods rich in antioxidants, exercising regularly, and maintaining a healthy body weight. Receiving regular eye exams from a young age can also protect an individual from the worsening of vision impairment.

Diagnosing Vision Impairment: Generally, the assessment process for determining if someone has vision impairment involves eye doctors, who:

1. Get an extensive individual history and family history of vision impairment from the patient.

2. Physically examine parts of the eye (e.g., lids, conjunctiva, cornea, iris, lens).

3. Administer the Snellen test. The Snellen test (also known as the visual acuity test) involves a chart containing progressively smaller letters and numbers that are placed 6 meters away from the patient. The patient must read the letters with each eye separately and together to determine their visual acuity.

4. Administer and the visual field test. The visual field test examines the range of vision a person can see without tilting or turning their head. A device is strapped to a patient's eyes, and then lights are flashed on and off in the patient's peripheral vision. The patient must press a button each time they see a light to determine any gaps in their field of vision.

5. Create a visual acuity score. The first number in the Snellen test represents the patient's distance from the chart at which they could accurately read the letters, and the second number represents the distance from the chart at which a person with healthy vision can read the letters. A score for healthy vision would be $6 / 6$. This means that a person with a score of $6 / 60$ would only read something 6 meters away that a person with healthy eyesight can read from 60 meters away. 


\section{Treating Vision Impairment:}

About $80 \%$ of vision impairment can be prevented or cured. Access to and utilization of preventative eye care is the most defensive tool against vision impairment. Specialized centers for eye disorders can provide people who are more susceptible to genetic vision impairment with adequate treatment to prevent eye disorders in their early stages. An extensive assessment is required to determine the genetic factors that put someone at risk for developing specific eye diseases.

Vision impairment cases involving uncorrected refractive errors or cataracts have readily available treatment methods. Options such as contact lenses, surgery, or glasses can help treat refractive errors. For cataracts, on the other hand, surgery is usually needed. Treatment is not currently available to completely cure blindness. The only option is to help detect early signs of blindness through testing vision loss and using family genetic history.

Researchers of vision impairment are currently in the process of studying the restoration of sight through stem cells. The use of stem cells would use a patient's own tissues to build new retinol pigmented epithelial cells (the cells that nourish retinal visual cells and absorb light). Potentially, the patient's visual cells could be prevented from being lost over time. 


\section{Appendix G: Mood Check Questionnaire/Empathic Concern and Personal Distress}

Directions: Please indicate the extent to which you are currently feeling each of the following emotions.

\begin{tabular}{|l|c|c|c|c|c|}
\hline & $\begin{array}{c}\mathbf{1} \\
\text { Very } \\
\text { Slightly or } \\
\text { Not at All }\end{array}$ & $\begin{array}{c}\mathbf{2} \\
\text { A little }\end{array}$ & $\begin{array}{c}\mathbf{3} \\
\text { Moderately }\end{array}$ & $\begin{array}{c}\mathbf{4} \\
\text { Quite a Bit }\end{array}$ & $\begin{array}{c}\mathbf{5} \\
\text { Extremely }\end{array}$ \\
\hline 1. Interested & 1 & 2 & 3 & 4 & 5 \\
\hline 2. Distressed & 1 & 2 & 3 & 4 & 5 \\
\hline 3. Excited & 1 & 2 & 3 & 4 & 5 \\
\hline 4. Upset & 1 & 2 & 3 & 4 & 5 \\
\hline 5. Strong & 1 & 2 & 3 & 4 & 5 \\
\hline 6. Guilty & 1 & 2 & 3 & 4 & 5 \\
\hline 7. Scared & 1 & 2 & 3 & 4 & 5 \\
\hline 8. Hostile & 1 & 2 & 3 & 4 & 5 \\
\hline 9. Enthusiastic & 1 & 2 & 3 & 4 & 5 \\
\hline 10. Proud & 1 & 2 & 3 & 4 & 5 \\
\hline 11. Irritable & 1 & 2 & 3 & 4 & 5 \\
\hline 12. Alert & 1 & 2 & 3 & 4 & 5 \\
\hline 13. Ashamed & 1 & 2 & 3 & 4 & 5 \\
\hline 14. Inspired & 1 & 2 & 3 & 4 & 5 \\
\hline 15. Nervous & 1 & 2 & 3 & 4 & 5 \\
\hline 16. Determined & 1 & 2 & 3 & 4 & 5 \\
\hline 17. Attentive & 1 & 2 & 3 & 4 & 5 \\
\hline 18. Jittery & 1 & 2 & 3 & 4 & 5 \\
\hline 19. Active & 1 & 2 & 3 & 4 & 5 \\
\hline 20. Afraid & 1 & 2 & 3 & 4 & 5 \\
\hline 21. Compassionate & 1 & 2 & 3 & 4 & 5 \\
\hline & 1 & 2 & 3 & 4 & 5 \\
\hline
\end{tabular}




\begin{tabular}{|l|c|c|c|c|c|}
\hline 22. Softhearted & 1 & 2 & 3 & 4 & 5 \\
\hline 23. Distressed & 1 & 2 & 3 & 4 & 5 \\
\hline 24. Alarmed & 1 & 2 & 3 & 4 & 5 \\
\hline 25. Warm & 1 & 2 & 3 & 4 & 5 \\
\hline 26. Disturbed & 1 & 2 & 3 & 4 & 5 \\
\hline 27. Moved & 1 & 2 & 3 & 4 & 5 \\
\hline 28. Tender & 1 & 2 & 3 & 4 & 5 \\
\hline 29. Uneasy & 1 & 2 & 3 & 4 & 5 \\
\hline $\begin{array}{l}\text { 30. Sympathetic } \\
\text { 31. Select "extremely" if } \\
\text { you're paying attention }\end{array}$ & 1 & 2 & 3 & 4 & 5 \\
\hline
\end{tabular}




\section{Appendix H: Social Comfort}

INSTRUCTIONS: Below are a number of statements about persons with dementia. Please circle the number that corresponds to the extent to which you agree/disagree with each statement.

\begin{tabular}{|c|c|c|c|c|c|c|c|}
\hline & 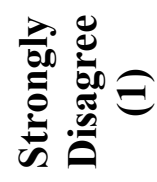 & 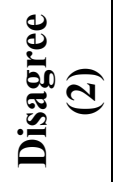 & 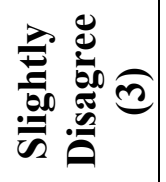 & 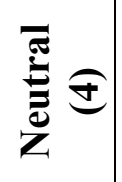 & 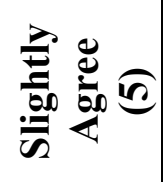 & 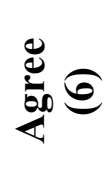 & 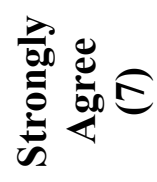 \\
\hline $\begin{array}{l}\text { 1. It is rewarding to work } \\
\text { with people who have } \\
\text { dementia. }\end{array}$ & 1 & 2 & 3 & 4 & 5 & 6 & 7 \\
\hline $\begin{array}{l}\text { 2. I feel confident around } \\
\text { people with dementia. }\end{array}$ & 1 & 2 & 3 & 4 & 5 & 6 & 7 \\
\hline $\begin{array}{l}\text { 3. I am comfortable } \\
\text { touching people with } \\
\text { dementia. }\end{array}$ & 1 & 2 & 3 & 4 & 5 & 6 & 7 \\
\hline $\begin{array}{l}\text { 4. I feel relaxed around } \\
\text { people with dementia. }\end{array}$ & 1 & 2 & 3 & 4 & 5 & 6 & 7 \\
\hline $\begin{array}{l}\text { 5. I am afraid of people } \\
\text { with dementia. }\end{array}$ & 1 & 2 & 3 & 4 & 5 & 6 & 7 \\
\hline $\begin{array}{l}6 \text {. I feel uncomfortable } \\
\text { being around people with } \\
\text { dementia. }\end{array}$ & 1 & 2 & 3 & 4 & 5 & 6 & 7 \\
\hline $\begin{array}{l}\text { 7. I am not very familiar } \\
\text { with dementia. }\end{array}$ & 1 & 2 & 3 & 4 & 5 & 6 & 7 \\
\hline $\begin{array}{l}\text { 8. I would avoid an agitated } \\
\text { person with dementia. }\end{array}$ & 1 & 2 & 3 & 4 & 5 & 6 & 7 \\
\hline $\begin{array}{l}\text { 9. I feel frustrated because I } \\
\text { do not know how to help } \\
\text { people with dementia. }\end{array}$ & 1 & 2 & 3 & 4 & 5 & 6 & 7 \\
\hline $\begin{array}{l}\text { 10. I cannot imagine taking } \\
\text { care of someone with } \\
\text { dementia. }\end{array}$ & 1 & 2 & 3 & 4 & 5 & 6 & 7 \\
\hline
\end{tabular}




\section{Appendix I: Dementia Worry}

INSTRUCTIONS: Below are a number of statements concerning personal feelings about dementia. Next to each statement, please indicate a number that corresponds to how often the statement applies to you.

\begin{tabular}{|c|c|c|c|c|c|}
\hline & 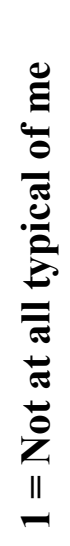 & 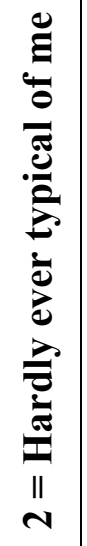 & 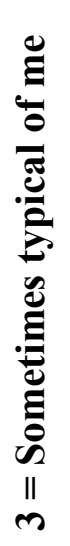 & 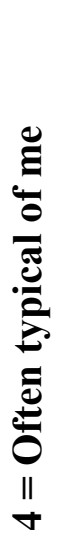 & 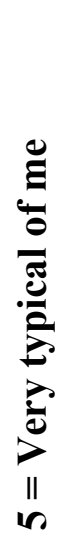 \\
\hline $\begin{array}{l}\text { 1. I know I shouldn't worry about developing dementia, but I just } \\
\text { cannot help it. }\end{array}$ & 1 & 2 & 3 & 4 & 5 \\
\hline $\begin{array}{l}\text { 2. I find it difficult to control my worries about developing } \\
\text { dementia. }\end{array}$ & 1 & 2 & 3 & 4 & 5 \\
\hline $\begin{array}{l}\text { 3. When I can't remember something, I find myself wondering } \\
\text { whether I have dementia. }\end{array}$ & 1 & 2 & 3 & 4 & 5 \\
\hline 4. My worries about dementia overwhelm me. & 1 & 2 & 3 & 4 & 5 \\
\hline $\begin{array}{l}\text { 5. More often than not, I find my thoughts returning to concerns that } \\
\text { I have dementia. }\end{array}$ & 1 & 2 & 3 & 4 & 5 \\
\hline $\begin{array}{l}\text { 6. When I hear about someone having dementia, I start to worry } \\
\text { about having it myself. }\end{array}$ & 1 & 2 & 3 & 4 & 5 \\
\hline $\begin{array}{l}\text { 7. When I am not distracted, I find my thoughts focusing on my own } \\
\text { cognitive changes and concerns. }\end{array}$ & 1 & 2 & 3 & 4 & 5 \\
\hline $\begin{array}{l}\text { 8. Even though I know it doesn't help to focus on it, I can't help } \\
\text { thinking about whether or not I have dementia. }\end{array}$ & 1 & 2 & 3 & 4 & 5 \\
\hline 9. Once I start worrying about dementia, I just cannot stop. & 1 & 2 & 3 & 4 & 5 \\
\hline $\begin{array}{l}\text { 10. Sometimes when trying to go to sleep, I find my thoughts drift } \\
\text { to my concerns about having dementia. }\end{array}$ & 1 & 2 & 3 & 4 & 5 \\
\hline
\end{tabular}




\begin{tabular}{|l|c|c|c|c|c|}
\hline \multicolumn{1}{|l|}{$\begin{array}{l}\text { 11. When I forget a word that I want to say, my thoughts } \\
\text { immediately turn to dementia. }\end{array}$} & 1 & 2 & 3 & 4 & 5 \\
\hline $\begin{array}{l}\text { 12. I think I probably worry more about dementia than other people } \\
\text { my same age. }\end{array}$ & 1 & 2 & 3 & 4 & 5 \\
\hline
\end{tabular}




\section{Appendix J: Personal Dementia Fear}

INSTRUCTIONS: Below are a number of statements concerning personal feelings about dementia. Next to each statement, please circle a number that corresponds to how often the statement applies to you.

\begin{tabular}{|c|c|c|c|c|c|}
\hline & $\begin{array}{c}\text { Never } \\
(1)\end{array}$ & $\begin{array}{c}\text { Rarely } \\
(2)\end{array}$ & $\begin{array}{c}\text { Sometimes } \\
\text { (3) }\end{array}$ & $\begin{array}{c}\text { Often } \\
(4)\end{array}$ & $\begin{array}{c}\text { Always } \\
\text { (5) }\end{array}$ \\
\hline $\begin{array}{l}\text { 1. The older I get, the more fearful I } \\
\text { become that I may develop } \\
\text { dementia }\end{array}$ & 1 & 2 & 3 & 4 & 5 \\
\hline 2. I am afraid of losing my memories & 1 & 2 & 3 & 4 & 5 \\
\hline $\begin{array}{l}\text { 3. The worse my memory becomes, } \\
\text { the more I fear that I may have } \\
\text { dementia. }\end{array}$ & 1 & 2 & 3 & 4 & 5 \\
\hline $\begin{array}{l}\text { 4. I sometimes think that I am } \\
\text { developing dementia. }\end{array}$ & 1 & 2 & 3 & 4 & 5 \\
\hline $\begin{array}{l}\text { 5. Even though my memory is good, I } \\
\text { am still afraid of developing } \\
\text { dementia. }\end{array}$ & 1 & 2 & 3 & 4 & 5 \\
\hline $\begin{array}{l}\text { 6. When I misplace things, I } \\
\text { sometimes think that I may have } \\
\text { dementia }\end{array}$ & 1 & 2 & 3 & 4 & 5 \\
\hline $\begin{array}{l}\text { 7. When I hear about others with } \\
\text { dementia, I become fearful that I } \\
\text { will get it as well. }\end{array}$ & 1 & 2 & 3 & 4 & 5 \\
\hline $\begin{array}{l}\text { 8. I think that I will probably get } \\
\text { dementia, and it frightens me. }\end{array}$ & 1 & 2 & 3 & 4 & 5 \\
\hline $\begin{array}{l}\text { 9. The more I learn about dementia, } \\
\text { the more fearful I become of getting } \\
\text { it. }\end{array}$ & 1 & 2 & 3 & 4 & 5 \\
\hline $\begin{array}{l}\text { 10. Developing dementia frightens me } \\
\text { because I would eventually lose all } \\
\text { of my independence. }\end{array}$ & 1 & 2 & 3 & 4 & 5 \\
\hline
\end{tabular}




\begin{tabular}{|l|l|l|l|l|l|}
\hline $\begin{array}{c}\text { 11. I am afraid of getting dementia } \\
\text { because I would have to rely on } \\
\text { someone else to take care of me. }\end{array}$ & 1 & 2 & 3 & 4 & 5 \\
\hline
\end{tabular}




\section{Appendix K: Explicit Dementia Attitudes (Dementia Allophilia Scale)}

INSTRUCTIONS: Below are a number of statements about persons with dementia. Please circle the number that corresponds to the extent to which you agree or disagree with each statement.

\begin{tabular}{|l|c|c|c|c|c|c|}
\hline & & & & & & \\
\hline $\begin{array}{l}\text { 1. In general, I have positive attitudes about } \\
\text { people with dementia }\end{array}$ & 1 & 2 & 3 & 4 & 5 & 6 \\
\hline $\begin{array}{l}\text { 2. I respect people with dementia } \\
\text { 3. I like people with dementia }\end{array}$ & 1 & 2 & 3 & 4 & 5 & 6 \\
\hline $\begin{array}{l}\text { 4. I feel positively toward people with } \\
\text { dementia }\end{array}$ & 1 & 2 & 3 & 4 & 5 & 6 \\
\hline $\begin{array}{l}\text { 5. I am at ease around people with dementia } \\
\text { 6. I am comfortable when I hang out with } \\
\text { people with dementia }\end{array}$ & 1 & 2 & 3 & 4 & 5 & 6 \\
\hline $\begin{array}{l}\text { 7. I feel like I can be myself around people } \\
\text { with dementia }\end{array}$ & 1 & 2 & 3 & 4 & 5 & 6 \\
\hline $\begin{array}{l}\text { 8. I feel a sense of belonging with people } \\
\text { with dementia }\end{array}$ & 1 & 2 & 3 & 4 & 5 & 6 \\
\hline $\begin{array}{l}\text { 9. I feel a kinship with people with } \\
\text { dementia }\end{array}$ & 1 & 2 & 3 & 4 & 5 & 6 \\
\hline $\begin{array}{l}\text { 10. I am truly interested in understanding the } \\
\text { points of view of people with dementia } \\
\text { with dementia better }\end{array}$ & 1 & 2 & 3 & 4 & 5 & 6 \\
\hline $\begin{array}{l}\text { 11. I am mo enrich my life, I would try and make } \\
\text { dementia }\end{array}$ & 1 & 2 & 3 & 4 & 5 & 6 \\
\hline
\end{tabular}




\begin{tabular}{|l|c|c|c|c|c|c|}
\hline $\begin{array}{l}\text { 13. I am interested in hearing about the } \\
\text { experiences of people with dementia }\end{array}$ & 1 & 2 & 3 & 4 & 5 & 6 \\
\hline 14. I am impressed by people with dementia & 1 & 2 & 3 & 4 & 5 & 6 \\
\hline 15. I am inspired by people with dementia & 1 & 2 & 3 & 4 & 5 & 6 \\
\hline $\begin{array}{l}\text { 16. I am enthusiastic about people with } \\
\text { dementia }\end{array}$ & 1 & 2 & 3 & 4 & 5 & 6 \\
\hline
\end{tabular}




\section{Appendix L: Manipulation Check}

1. What were the questions you just read about?

2. How interested were you in reading about dementia (circle number below)?

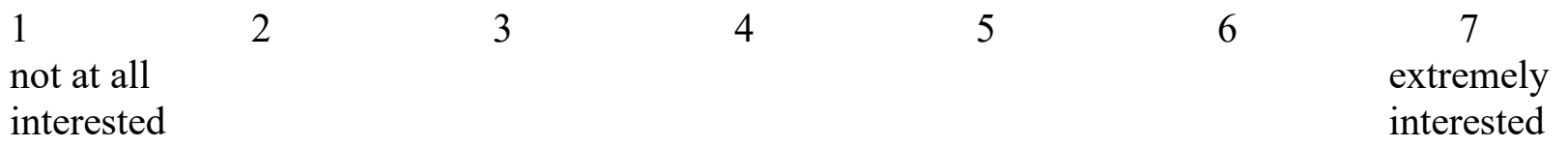

3. Please briefly describe in $2-3$ sentences what you read about in the first part of the study: 


\section{Appendix M: Demographics}

1. Sex (circle one): Male Female Other(please specify):

2. Age:

3. Ethnicity (Check all that apply):

African-American

Asian

Caucasian

Hispanic

Middle Eastern

Native American (American Indian)

Multi-racial (Please also check all ethnicities you identify with)

Other

4. Relationship Status

Single
Married
Divorced
Separated
Living with partner

5. In what city and state do you currently live?

6. What city and state would you consider your hometown?

7. How would you describe your hometown? (please choose one)
a. Rural $(2,500$ or fewer residents)
b. Small town (more than 2,500 but fewer than 20,000)
c. Town/small city (20,000-100,000 resident)
d. Large city (more than 100,000 residents)

8. What is your highest level of education?
a. GED
b. High School
c. Some College
d. College Degree
e. Graduate Degree or other training post-college
f. Other 
9. What is your annual household income?
a. Less than $\$ 20,000$
b. $\$ 20,000$ - $\$ 29,999$
c. $\$ 30,000$ - $\$ 39,999$
d. $\$ 40,000$ - $\$ 49,999$
e. $\$ 50,000$ - $\$ 59,999$
f. $\$ 60,000-\$ 69,999$
g. $\$ 70,000$ or more

10. What is your current job or occupation status? (please choose one)
a. Working full time
b. Working part time
c. Homemaker
d. Student
e. Unemployed - looking for work
f. Retired
g. Disabled - unable to work

11. Do you have any living or non-living family members with dementia?
a. Yes, living
b. Yes, deceased
c. No

12. (If yes to 11): How many family members with dementia do you have?

13. (If yes to 11): Regarding your family member with dementia:

- To what extent are/were you involved in providing care (please indicate on scale of 0 , not involved at all, to 10, extremely involved):

14. Do you know any non-family members with dementia (e.g., do you have any neighbors, friends, or acquaintances with dementia)?

- Yes, living

- Yes, deceased

- No

15. (If yes to 14): How many people (excluding family members) do you know with dementia?

16. (If yes to 14): Regarding your non-family member with dementia:

- To what extent are/were you involved in providing care (please indicate on scale of 0, not involved at all, to 10, extremely involved):

17. What is your occupation?

18. In what year were you born?

19. Do you work with people with dementia as a part of your occupation? 


\section{Appendix N: Debriefing}

Thank you for participating in this study. The purpose of this page is to provide you more in-depth information about the study. The purpose of this study was to examine how knowledge about dementia may influence your thoughts, feelings, and attitudes towards persons with dementia, as well as your worries regarding one day developing dementia.

Previous research has indicated that in general, people with more knowledge about dementia may feel more comfortable around persons with dementia, worry less about developing dementia, and have more positive attitudes toward people with dementia.

In this study, participants were randomized into one of five groups: (1) a biomedical knowledge group, in which they learned about the biological and medical facts about dementia, (2) a personhood-based knowledge group, in which they learned about the personal experiences, capabilities, and perspectives of persons with dementia, (3) a combined knowledge group, in which they were given both the biomedical and personhood-based knowledge readings, (4) a baseline control group, in which participants did not read about dementia, or (5) an active control group, in which participants read about vision impairment. We then had participants answer questions about their attitudes, comfort, and worry about dementia. We will use this information to compare how people's attitudes, comfort, and worry about dementia differ based on the information they are given about dementia.

It is important to remember that there is no correct or incorrect emotional response to any of the questionnaires or materials in this study. However, if you have any concerns about this study, then please speak with Dr. Amy Fiske, the primary investigator, about your concerns (Amy.Fiske@mail.wvu.edu). She will be more than happy to talk with you about any concerns you may have. Similarly, if you would like copies of the information sheets about dementia, please email Dr. Amy Fiske (Amy.Fiske@mail.wvu.edu).

Again, thank you very much for your participation. We value the time and energy you spent in this study and it is our hope that the data you have provided will help us to better understand human psychology.

\section{You must acknowledge that you've read the debriefing form before you get your completion code.}

- Yes, I read the form

- No, I did not read the form 